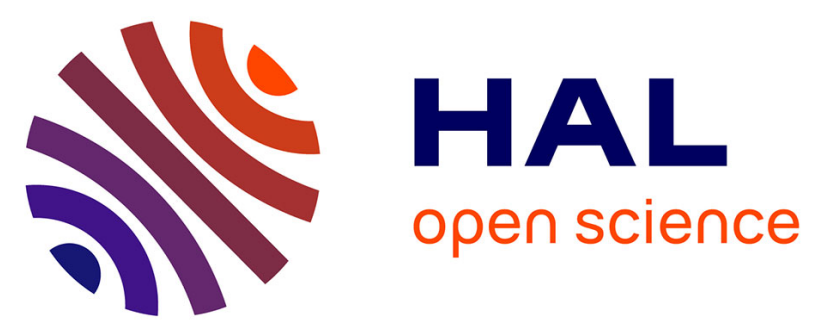

\title{
Development and characterization of single-domain antibodies neutralizing protease nexin-1 as tools to increase thrombin generation
}

\author{
Charlotte Kawecki, Karen Aymonnier, Stephen Ferrière, Laurence Venisse, \\ Véronique Arocas, Yacine Boulaftali, Olivier D Christophe, Peter J. Lenting, \\ Marie-Christine Bouton, Cécile V Denis
}

\section{To cite this version:}

Charlotte Kawecki, Karen Aymonnier, Stephen Ferrière, Laurence Venisse, Véronique Arocas, et al.. Development and characterization of single-domain antibodies neutralizing protease nexin- 1 as tools to increase thrombin generation: Single-domain antibodies against protease nexin-1. Journal of Thrombosis and Haemostasis, 2020, 18, pp.2155-2168. 10.1111/jth.14940 . inserm-02934843

\section{HAL Id: inserm-02934843 https://www.hal.inserm.fr/inserm-02934843}

Submitted on 9 Sep 2020

HAL is a multi-disciplinary open access archive for the deposit and dissemination of scientific research documents, whether they are published or not. The documents may come from teaching and research institutions in France or abroad, or from public or private research centers.
L'archive ouverte pluridisciplinaire HAL, est destinée au dépôt et à la diffusion de documents scientifiques de niveau recherche, publiés ou non, émanant des établissements d'enseignement et de recherche français ou étrangers, des laboratoires publics ou privés. 


\section{Development and characterization of single-domain antibodies neutralizing protease nexin-1 as tools to increase thrombin generation}

Charlotte Kawecki ${ }^{1,2^{*}}$, Karen Aymonnier ${ }^{*}$, Stephen Ferrière ${ }^{1}$, Laurence Venisse ${ }^{2}$, Véronique Arocas $^{2}$, Yacine Boulaftali ${ }^{2}$, Olivier D. Christophe ${ }^{1}$, Peter J Lenting ${ }^{1}$, Marie-Christine Bouton ${ }^{2}$, Cécile V. Denis ${ }^{1}$

${ }^{1}$ Institut National de la Santé et de la Recherche Médicale, UMR_S 1176, Univ. Paris-Sud, Université Paris-Saclay, 94276 Le Kremlin-Bicêtre, France

${ }^{2}$ Institut National de la Santé et de la Recherche Médicale, UMR_S 1148, Université de Paris, 75018 Paris, France.

* : Equal contribution

Corresponding author:

Cécile V. Denis

INSERM U1176

80 rue du General Leclerc

94276 Le Kremlin-Bicêtre cedex

Tel: +33-1-49-59-56-00

Fax: +33-1-46-71-94-72

Email: cecile.denis@inserm.fr

Abstract: $\quad 246$ words

Main text (Introduction, Material and Methods, Results, Discussion) 4823 words

Figures: $\quad 6$

References: 29

Running title: Single-domain antibodies against protease nexin-1 


\section{ESSENTIALS}

- Protease nexin-1 (PN-1) belongs to the serpin-family and is an inhibitor of thrombin

- Most antibodies targeting PN-1 cross-react with plasminogen activator inhibitor-1

- We isolated single-domain antibodies (VHHs) that specifically bind and neutralize PN1 activity towards thrombin

- These VHHs represent novel tools to study the biology of PN-1 in general and in hemostasis in particular

\section{ABSTRACT}

Background: Protease nexin-1 (PN-1) is a member of the serine protease inhibitor (Serpin)family, with thrombin as its main target. Current polyclonal and monoclonal antibodies against PN-1 frequently cross-react with Plasminogen activator inhibitor-1 (PAl-1), a structurally and functionally homologous Serpin.

Objectives: Here, we aimed to develop inhibitory single-domain antibodies (VHHs) that show specific binding to both human (hPN-1) and murine (mPN-1) PN-1.

Methods: PN-1-binding VHHs were isolated via phage-display using llama-derived or synthetic $\mathrm{VHH}$-libraries. Following bacterial expression, purified $\mathrm{VHHs}$ were analyzed in binding and activity assays.

Results and Conclusions: By using a llama-derived library, $2 \mathrm{PN}-1$ specific VHHs were obtained (KB-PN1-01 \& KB-PN1-02). Despite their specificity, none displayed inhibitory activity towards hPN-1 or mPN-1. From the synthetic library, $4 \mathrm{VHHs}(\mathrm{H} 12, \mathrm{~B} 11, \mathrm{~F} 06, \mathrm{A08})$ could be isolated that combined efficient binding to both $\mathrm{hPN}-1$ and $\mathrm{mPN}-1$ with negligible binding to PAI-1. Of these, B11, F06 and A08 were able to fully restore thrombin activity by blocking PN-1. As monovalent $\mathrm{VHH}, \mathrm{IC} 50$-values for $\mathrm{hPN}-1$ were $50 \pm 10 \mathrm{nM}, 290 \pm 30$ and $960 \pm 390 \mathrm{nM}$, for B11, F06 and A08, respectively, and 1580 $\pm 240 \mathrm{nM}, 560 \pm 130 \mathrm{nM}$ and $2880 \pm 770 \mathrm{nM}$ for $\mathrm{mPN}-1$. The inhibitory potential was improved 4- to 7-fold when bivalent VHHs were engineered. Importantly, all VHHs could block PN-1 activity in plasma as well as $\mathrm{PN}-1$ released from activated platelets, one of the main sources of $\mathrm{PN}-1$ during hemostasis. In conclusion, we report the generation of inhibitory anti-PN-1 antibodies using a specific approach to avoid cross-reactivity with the homologous Serpin PAI-1.

Key words: Serpin, protease nexin-1, single-domain antibody, phage display, thrombin 


\section{INTRODUCTION}

Protease nexin-1 (PN-1) belongs to a family of structurally related proteins known as inhibitors of serine protease or serpins, which can be found in most organisms. ${ }^{1}$ Serpins use their reactive center loops $(R C L)$ to target the active site of serine proteases, driving the complex into a suicide substrate inhibition mechanism. This leads to inactivation of the protease and often rapid clearance via scavenger-receptors.

Phylogenetically, $\mathrm{PN}-1$ is most closely related to plasminogen activator inhibitor 1 (PAl-1) with $41 \%$ shared sequence. ${ }^{2} \mathrm{PN}-1$ is undetectable in the circulating blood, but is present in circulating cells (monocytes and platelets) and vascular cells. ${ }^{3} \mathrm{PN}-1$ is secreted during platelet activation and efficiently inhibits thrombin, the key enzyme of the coagulation cascade which catalyzes fibrin formation. ${ }^{4}$ Besides thrombin, $\mathrm{PN}-1$ inhibits several other serine proteases, albeit much less efficient, such as trypsin, tissue-type plasminogen activator, urokinase-type plasminogen activator (u-PA), plasmin, factor $\mathrm{Xa}$, factor Xla , activated protein $\mathrm{C}$ and factor $\mathrm{VII}$ activating protease..$^{5-9}$ Its physiological role extends to several processes, like coagulation, fibrinolysis and tissue remodelling. ${ }^{3,4,10}$

Recently, we have investigated the impact of PN-1 inhibition on coagulation in both mice and patients with haemophilia. Interestingly, polyclonal antibody-mediated inhibition of PN-1 in haemophilic patient plasma led to an increase of thrombin generation and of clot strength, as well as a reduction of fibrinolysis. Furthermore, the bleeding phenotype of haemophilic mice is mitigated by $\mathrm{PN}-1$ deficiency. Inhibition of $\mathrm{PN}-1$ could thus potentially be used to restore the haemostatic balance between pro-and anticoagulant systems in haemophilia. ${ }^{11}$ This observation is in line with current developments of new therapeutics in the haemophilia field, which aim for restoring this balance by neutralizing natural anticoagulants: Targeting of antithrombin expression by small interfering RNA, of tissue factor pathway inhibitor by antibodies or of activated protein $\mathrm{C}$ by an engineered serpin are all strategies currently under investigation. ${ }^{12-14}$

Currently, there is a lack of specific anti-PN-1 antibodies that could block PN-1 function. Very few monoclonal and polyclonal inhibitory anti-PN-1 antibodies are available, and many of them (including those that are commercially available) cross-react with the closest PN-1 family member, PAI-1. We therefore chose to develop single domain-antibodies (VHHs) targeting $\mathrm{PN}-1$. VHHs have many inherent, advantageous properties, such as their low molecular mass (15 kDa), low immunogenicity, high affinity, high solubility and stability and easy production in bacteria. ${ }^{15-17}$ In comparison with classical immunoglobulins, VHHs display hypervariable complementary determining regions (CDRs), which can recognize specific epitopes that are less accessible, or buried deep in structural clefts. ${ }^{18}$ Furthermore, VHHs are often potent inhibitors of proteins, due to their long CDR3 domain, which is able to penetrate 
into the catalytic cleft of enzymes. ${ }^{19}$ Taken together, these characteristics led us to hypothesize that the generation of inhibitory VHHs against PN-1 could generate new tools to study the impact of PN-1 inhibition in haemostasis. We report the isolation of three specific inhibitory VHHs against PN-1. 


\section{MATERIALS \& METHODS}

\section{Materials}

Isopropyl $\beta$-D-1-thiogalactopyranoside (IPTG), Human serum albumin (HSA), Bovine serum albumin (BSA) were from Sigma-Aldrich (Saint-Quentin Fallavier, France). Polyclonal Rabbit anti-cMyc tag peroxidase-labelled, polyclonal rabbit anti-6xHis-tag antibodies were from Abcam (Paris, France). Human and murine PN-1 and human $\alpha$-thrombin were prepared as described. ${ }^{20,21}$ PT and aPTT reagents were from Stago-Diagnostica (Asnières-sur-Seine, France). Chromogenic substrates PNAPEP-1344 and PNAPEP-0238 were from Cryopep (Montpellier, France). Dynabeads M-450 epoxy beads, E.coli TG1 cells, Terrific Broth (TB)medium, Lysogeny Broth (LB)-medium were from ThermoFisher Scientific (Villebon-surYvette, France). Plasminogen activator inhibitor-1 (PAl-1) was from Stago BNL (Lille, France). AEBSF was from vWR (Fontenay-sous-Bois, France).

\section{Construction of anti-PN-1 VHHs from lymphocytes library by phage display}

Immunization of a single llama (L. glama) was outsourced to the Centre de Recherche en Cancérologie (Université Aix-Marseille, Marseille, France). ${ }^{22}$ Briefly, the llama was immunized with $100 \mu \mathrm{g}$ of a mix of human or murine PN-1 in equal proportion with Freund's incomplete adjuvant. After blood sampling, mRNA was extracted from lymphocytes and the VHH-library was constructed as described. ${ }^{22-24}$ The library contains VHH-coding DNA fragments, which were cloned into the pHEN6-phagemid vector and transformed in electrocompetent E.coli TG1 cells ${ }^{25}$ (ThermoFischer Scientitic) to generate a library of $0.9 \times 10^{8}$ clones. The M13K07 phage helper was used to infect the TG1 VHH-library to allow surface expression of the $\mathrm{VHHs}$.

\section{Negative and positive selection of VHHs}

To reduce the number of $\mathrm{VHHs}$ cross-reacting with $\mathrm{PAI}-1$, phage particles were first incubated with beads coated with $100 \mu \mathrm{g} \mathrm{PAI}-1$ (1h at room temperature in PBS-3\% BSA). Non-binding phages were passed on beads coated with a mixture of murine PN-1 and

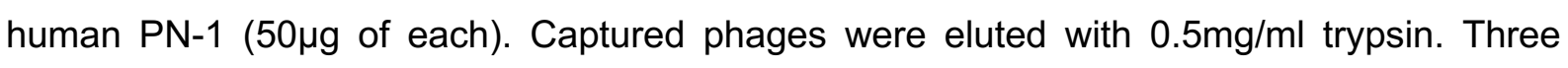
consecutive rounds of enrichment were performed.

\section{Selection of anti-PN1-specific VHHs.}

After infection of TG1 bacteria with isolated phages, cells were grown $4 \mathrm{~h}$ under agitation in TB-medium, then $1 \mathrm{mM}$ IPTG was added to induce VHH expression at $30^{\circ} \mathrm{C}$. Eighteen hours after induction, cells were centrifuged and periplasmic extract was collected after lysis in TES-buffer (200mM Tris-HCl, pH8, 0.5mM EDTA and 500mM sucrose) for $1 \mathrm{~h}$ at $4^{\circ} \mathrm{C}$ followed 
by 30min with TES-buffer diluted 4-fold in PBS. Released soluble proteins were tested for binding to PN-1, PAI-1 or BSA. Proteins $(1 \mu \mathrm{g} /$ well) were coated on NUNC Maxisorp-plates (ThermoFischer Scientific) in PBS, overnight at $4^{\circ} \mathrm{C}$. After saturation, (PBS-BSA 3\%, $1 \mathrm{~h}$ at $37^{\circ} \mathrm{C}$ ), bound $\mathrm{VHHs}$ were probed using alkaline phosphatase-coupled polyclonal anti-6xHistag antibody, detected via hydrolysis of 3,3',5,5'-tetramethylbenzidine (TMB) and absorbance was read at $450 \mathrm{~nm}$.

\section{Isolation of anti-PN-1 VHH from a synthetic library}

In a second approach, a synthetic VHH library was used to isolate anti-PN-1 VHHs (Hybrigenics Services SAS, Paris, France). This hs2dAb phage-display library containing $3 \times 10^{9} \mathrm{VHHs}$ was first incubated with human PAI-1-coated beads to reduce unspecific binders. Unbound $\mathrm{VHHs}$ were then incubated with murine or human $\mathrm{PN}-1$-coated beads. A total of three rounds of phage display were performed, with the depletion step being repeated during each round. After 3 rounds, $90 \mathrm{E}$. coli clones were picked randomly and analyzed for binding to human and murine $\mathrm{PN}-1$ as well as PAl-1. Phage-clones showing $>5$-fold increased signal to PN-1 over PAl-1 were considered as specific binders for PN-1 (mouse, human or both). Sequencing of the positive clones revealed the presence of 18 different positive VHHs. Four of these recognized both $\mathrm{mPN}-1$ and $\mathrm{hPN}-1$, and were subcloned in the pHEN2-vector for further characterization.

\section{VHH subcloning, expression and purification}

Anti-PN-1 VHHs were transformed directly into E. coli WK6 cells. Each clone was first grown in $10 \mathrm{~mL}$ LB-medium $/ 100 \mu \mathrm{g} / \mathrm{mL}$ ampicillin/2\% glucose $/ 1 \mathrm{mM} \mathrm{MgCl}_{2}$ overnight at $37^{\circ} \mathrm{C}$ under gentle agitation. $3 \mathrm{~mL}$ of this preculture was used to inoculate $330 \mathrm{~mL}$ of TBmedium $/ 100 \mu \mathrm{g} / \mathrm{mL}$ ampicillin $/ 0.1 \%$ glucose $/ 1 \mathrm{mM} \mathrm{MgCl}$. The culture agitated $\left(170 \mathrm{rpm}, 37^{\circ} \mathrm{C}\right.$ ) until it reached an $\mathrm{OD}_{600}$ between 0.8 and 1 . $\mathrm{VHH}$ expression was then induced by $1 \mathrm{mM}$ IPTG and the medium was left to grow overnight $\left(170 \mathrm{rpm}, 28^{\circ} \mathrm{C}\right)$. The periplasmic proteins were extracted by sonication (Fisher scientific, Illkirch, France) during $30 \mathrm{~min}$ with a cycle 10 seconds ON/10 seconds OFF. The percentage of lysis was verified by a ratio (OD after lysis/OD before lysis) $x$ 100. His-tagged VHHs were next purified via $\mathrm{Co}^{2+}$-affinity chromatography as instructed (VWR). Minor contaminants were removed via size-exclusion chromatography using $20 \mathrm{mM}$ Hepes $(\mathrm{pH} 7.4) / 0.1 \mathrm{M} \mathrm{NaCl}$ as equilibrium-buffer. Purified VHHs displayed $>95 \%$ homogeneity as assessed via SDS-Page and Coomassie-staining.

For bivalent $\mathrm{VHHs}$, two copies of monovalent sdAbs were separated by a linker consisting of [GGGs] $]_{3}$ and a C-terminal 6xHis-Tag allowed for purification via $\mathrm{Co}^{2+}$-affinity chromatography. 


\section{hPAl-1 and mPAl-1 ELISA}

Immulon 2-plates were coated with a murine monoclonal antibody to mPAl-1 or hPAl-1 $(0.4 \mu \mathrm{g} / \mathrm{well} ;$ Bio-Techne, Rennes, France) overnight at room temperature. After washing with PBS-tween-20 0.05\%, wells were saturated with PBS-BSA $1 \%, 1 \mathrm{~h}$ at room temperature. After washing, human or murine PAl-1 $(2 \mathrm{pg} / \mathrm{mL})$ were incubated for $2 \mathrm{~h}$ at room temperature. Then, $\mathrm{VHHs}(10 \mu \mathrm{g} / \mathrm{mL})$ were incubated $2 \mathrm{~h}$ at room temperature. Bound $\mathrm{VHHs}$ were probed with a peroxidase-labelled polyclonal anti-6xHis-tag antibody and detected via hydrolysis of TMB and absorbance was read at 450nm.

\section{hPN-1 and mPN-1 ELISA}

Microlon-Med half-wells plates (Greiner bio-one, Courtaboeuf, France) were coated with $0.5 \mu \mathrm{gPN}-1$ or $\mathrm{hPN}-1 /$ well overnight at $4^{\circ} \mathrm{C}$ and then incubated with different concentrations of VHHs (0 to $20 \mu \mathrm{g} / \mathrm{mL}$ ) in PBS/BSA $0.1 \% /$ Tween-20 $0.1 \%$ for $2 \mathrm{~h}$ at $37^{\circ} \mathrm{C}$. Bound anti-PN-1 VHHs were probed with peroxidase-labelled polyclonal anti-cMyc tag antibody for monovalent $\mathrm{VHHs}$ or anti-6xHis-tag antibody for bivalent $\mathrm{VHHs}$ in the same buffer and detected via hydrolysis of TMB and absorbance was read at $450 \mathrm{~nm}$.

\section{Inhibition of thrombin activity by PN-1}

In a 96-wells plate (Greiner Bio-one) various concentrations of anti-PN-1 VHHs were incubated with $10 \mathrm{nM} \mathrm{PN}-1$ during $15 \mathrm{~min}$ at room temperature in $20 \mathrm{mM}$ Hepes/0.15M NaCl/ $0.1 \%$ HSA. $1 \mathrm{nM}$ purified thrombin was then added to the wells and incubated $30 \mathrm{~min}$ at room temperature. Thrombin activity was quantified by measuring the rate of $p$-nitroaniline release from the chromogenic substrate H-D-Phe-Pip-Arg-pNA (PNAPEP-0238) (0.2mM), at $37^{\circ} \mathrm{C}$ and read at $405 \mathrm{~nm}$ in a multiwell plate reader.

To calculate the IC50 of each $\mathrm{VHH}$, a slightly modified protocol was used: anti-PN-1 VHHs were used at concentrations between 0 and $2 \mu \mathrm{M}$, incubation of $\mathrm{VHHs}$ was performed during $5 \mathrm{~min}$ followed by $10 \mathrm{~min}$ incubation with $1 \mathrm{nM}$ thrombin. PNAPEP-0238 substrate was added at a concentration of $0.2 \mathrm{mM}$ and incubated for $2 \mathrm{~h}$ at $37^{\circ} \mathrm{C}$. Quantification of thrombin activity was performed as described above.

\section{Inhibition thrombin activity by endogenous PN-1}

Blood samples were taken in ACD-A anticoagulant tubes. Blood was centrifuged at $120 \mathrm{~g}$ during $15 \mathrm{~min}$ to recover the platelet rich plasma (PRP). Then, $2 \mu \mathrm{L} / \mathrm{mL}$ apyrase $(5 \mathrm{mg} / \mathrm{mL})$ and $1 \mu \mathrm{L} / \mathrm{mL}$ PGE1 $(10 \mathrm{mM})$ were added and the PRP was centrifuged at $1200 \mathrm{~g}, 12 \mathrm{~min}$ at $20^{\circ} \mathrm{C}$. The pellet was resuspended gently in washing buffer $(3.6 \mathrm{mM}$ citric acid, $0.5 \mathrm{mM}$ glucose, $0.5 \mathrm{mM} \mathrm{KCl}, 10.3 \mathrm{mM} \mathrm{NaCl}, 2 \mathrm{mM} \mathrm{CaCl} 2 \mathrm{pH} 6.5,0.30 \%$ BSA, $2 \mu \mathrm{L} / \mathrm{mL}$ apyrase $(5$ $\mathrm{mg} / \mathrm{mL})$ and $1 \mu \mathrm{L} / \mathrm{mL}$ PGE1 $(10 \mathrm{mM}))$ and centrifuged $12 \mathrm{~min}$ at $1200 \mathrm{~g}$ at $20^{\circ} \mathrm{C}$. The platelets 
were adjusted to a concentration of $5 \times 10^{8}$ cells $/ \mathrm{mL}$ in reaction buffer $(0.03 \mathrm{mM}$ NaH2PO4, $0.5 \mathrm{mM}$ Hepes, $0.55 \mathrm{mM}$ glucose, $0.2 \mathrm{mM} \mathrm{MgCl}_{2}, 0.1 \mathrm{mM} \mathrm{KCl}, 13.7 \mathrm{mM} \mathrm{NaCl}, 12 \mathrm{mM} \mathrm{NaHCO}_{3}$, $2 \mathrm{mM} \mathrm{CaCl}_{2}, \mathrm{pH} 7.3$ and $0.3 \% \mathrm{BSA}$ ). For the condition "activated platelets", $50 \mu \mathrm{M}$ of TRAP (Thrombin receptor activating peptide) was added to the platelets for $30 \mathrm{~min}$ at $37^{\circ} \mathrm{C}$. Platelet were centrifuged $1200 \mathrm{~g}$ for $10 \mathrm{~min}$ at room temperature to keep the supernatant.

In a 96-wells plate (Greiner Bio-one), $80 \mu \mathrm{L}$ of activated or non-activated platelets supernatant was spiked with $1 \mu \mathrm{M}$ of $\mathrm{VHHs}$ and incubated $15 \mathrm{~min}$ at room temperature. Then, $0.1 \mathrm{nM}$ of thrombin was added to each well and incubated $30 \mathrm{~min}$ at room temperature. PNAPEP-0238 substrate was added at a concentration of $0.2 \mathrm{mM}$ and incubated for $2 \mathrm{~h}$ at $37^{\circ} \mathrm{C}$. Quantification of thrombin activity was performed as described above.

\section{Inhibition of uPA (urokinase-type plasminogen activator) by human PAI-1}

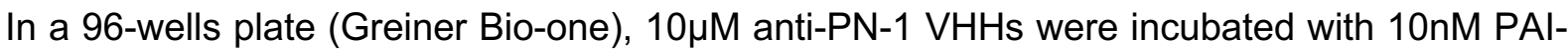
1 for $15 \mathrm{~min}$ at room temperature in $20 \mathrm{mM}$ Hepes $\mathrm{pH} 7.5,150 \mathrm{mM} \mathrm{NaCl}, 0.1 \% \mathrm{HSA}$, pH7.5. $1.3 \mathrm{nM}$ of uPA was subsequently added. After $10 \mathrm{~min}$ incubation at room temperature, wells were quantified for UPA activity by measuring the rate of p-nitroaniline release from the chromogenic substrate Glu-Gly-Arg-pNA, PNAPEP-1344 (0.2mM) at $37^{\circ} \mathrm{C}$ and read at 405 $\mathrm{nm}$ by a multiwell plate reader.

\section{Test of VHHs specificity by Biolayer interferometry (BLI)-analysis}

Equilibrium binding was performed via BLI-analysis using Octet QK-equipment (Fortebio, Reading, UK). Monovalent VHHs $(25 \mu \mathrm{g} / \mathrm{mL})$ diluted in $100 \mathrm{mM}$ MES (pH 5.0) were immobilized onto amine reactive biosensors. After quenching by ethanolamine, VHHs-coated sensors were incubated with human or murine PN-1 or human PAI-1 $(1 \mu \mathrm{M})$ in PBS-Tween $0.1 \%$ buffer for $15 \mathrm{~min}$ to allow association. Subsequently, biosensors were incubated in PBS-Tween $0.1 \%$ buffer for $10 \mathrm{~min}$ to initiate dissociation. In alternative experiments, $50 \mu \mathrm{g} / \mathrm{mL}$ biotinylated RCL of PN-1 was immobilized on streptavidine sensors in PBS- Tween $0.1 \%$ buffer. Before the association, $5 \mathrm{U}$ of thrombin or buffer PBS-Tween were incubated with sensor during $30 \mathrm{~min}$ at $37^{\circ} \mathrm{C}$ then the association of bivalent $\mathrm{VHHs}(100 \mu \mathrm{g} / \mathrm{mL})$ was followed for $15 \mathrm{~min}$ at $37^{\circ} \mathrm{C}$. Subsequently, biosensors were put in PBS-tween $0.1 \%$ buffer for $10 \mathrm{~min}$ to initiate dissociation. Data were analyzed using Octet Software version 4.0.

\section{Modified prothrombin time (PT)}

Fifty microliters of murine normal pooled plasma (MNPP) were diluted 8-fold in Owren-Koller

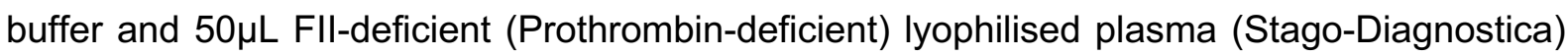
were added. The mix was incubated $15 \mathrm{~min}$ at $37^{\circ} \mathrm{C}$ with $62.5 \mathrm{nM}$ of $\mathrm{mPN}-1$ with or without $288 \mathrm{nM}$ bivalent VHHs. Prothrombin time was started by adding $100 \mu \mathrm{L}$ Neoplastin Cl (Stago- 
Diagnostica) to the mix. Clot formation was measured by coagulometer STArt, (StagoDiagnostica). Assays were performed three times in duplicates at $37^{\circ} \mathrm{C}$.

\section{Modified activated partial thromboplastin time (aPTT)}

Fifty microliters of FVIII-deficient murine plasma were diluted 8-fold in Owren-Koller buffer to which $50 \mu \mathrm{L}$ of FVIII-deficient lyophilised plasma and $50 \mu \mathrm{L}$ of PTT reagent (StagoDiagnostica) were added. After a 100 seconds incubation, $625 \mathrm{nM}$ VHHs and 500nM mPN-1 were added. After 240 seconds of incubation at $37^{\circ} \mathrm{C}$, the aPTT test was started by adding $100 \mu \mathrm{L} 0.025 \mathrm{M} \mathrm{CaCl}_{2}$. The clot formation was measured by a coagulometer. Assays were performed three times in duplicates at $37^{\circ} \mathrm{C}$.

\section{Statistical analysis}

Data are presented as mean with standard error (SD) and was analyzed using Prism software. One-way ANOVA analysis was utilized for values comparisons with control. Pvalues $<0.05 \& P<0.0001$ were considered as significant and highly significant respectively. 


\section{Results}

\section{Identification and characterization of VHHs obtained by llama immunization.}

The VHH library was obtained from mRNA of lymphocytes isolated 6 weeks after the first llama immunisation. Phage display was used to select VHHs specific for PN-1. The selection has been performed in two steps: first, we selected negatively all VHHs that did not bind to magnetic beads coated with PAl-1 in order to reduce the number of anti-PAI-1 VHHs, while the second step consisted in elution of all VHHs bound to magnetic beads coated with $\mathrm{PN}-1$. Such a two-step procedure was deemed necessary since PN-1 and PAI-1 contain conserved sequences. ${ }^{26}$ After 3 rounds of phage display, we obtained $1300 \mathrm{VHHs}$ that were subsequently screened (Fig. 1A). 377 VHHs (29\%) recognized hPN-1 and/or mPN-1 above the previously defined threshold (OD at least twice the OD obtained for the negative control, milk). Despite the negative selection on PAI-1, 375 of these $377 \mathrm{VHHs}$ recognized PAI-1 as well as PN-1. The 2 clones specific for PN-1 (KB-PN1-01 and KB-PN1-02) were expressed in E.coli Shuffle cells and purified for further characterization.

Kinetic analysis of the interaction between the $\mathrm{VHHs}$ and $\mathrm{hPN}-1, \mathrm{mPN}-1$ and hPAl-1 were analysed by biolayer interferometry. Both $\mathrm{VHHs}$ displayed efficient binding to hPN-1 with maximal binding being $4.9 \pm 0.1 \mathrm{~nm}$ and $5.1 \pm 0.1 \mathrm{~nm}$ for KB-PN1-01 and KB-PN1-02, respectively (Fig. 1B). Binding to $\mathrm{mPN}-1$ was less efficient with maximal binding being $2.0 \pm 0.1 \mathrm{~nm}$ and $1.9 \pm 0.1 \mathrm{~nm}$, respectively. Only low binding was observed for PAI-1 (maximal binding $0.6 \pm 0.2 \mathrm{~nm}$ and $0.6 \pm 0.1 \mathrm{~nm}$ ). Three bivalents variants were engineered, designated KB-PN1-01bv, KB-PN1-02bv and KB-PN1-0102. We next analyzed the capacity of the different $\mathrm{VHHs}$ to inhibit $\mathrm{PN}-1$ by measuring restoration of thrombin activity. As expected, in the presence of $\mathrm{hPN}-1$ or $\mathrm{mPN}-1$, thrombin activity was strongly decreased with a residual thrombin activity of $5 \pm 2 \%$ for $\mathrm{hPN}-1$ and $2 \pm 1 \%$ for $\mathrm{mPN}-1$ (Fig. 1C). Among the different VHHs, only KB-PN1-01 was able to partially neutralize $\mathrm{hPN}-1$ and $\mathrm{mPN}-1$, restoring residual thrombin activity to $31 \pm 5 \%$ for $\mathrm{hPN}-1$ and $13 \pm 1 \%$ for $\mathrm{mPN}-1$, respectively (Fig. 1C). All other $\mathrm{VHH}$ variants proved unable to inhibit hPN-1 or mPN-1 (Fig. 1C). Thus, despite the identification of $\mathrm{VHHs}$ specific for $\mathrm{PN}-1$, these variants were unfortunately unable to efficiently inhibit its action towards thrombin.

\section{Developing anti-PN-1 VHHs from a synthetic VHHs library.}

To obtain specific potent inhibitory anti-PN-1 VHHs, we next moved to a synthetic VHH library. ${ }^{27}$ The $\mathrm{VHH}$ were selected using the same protocol used for classical VHHs. The 4 strongest binders were selected for further characterization: H12, B11, F06 and A08, whose sequences are indicated in Fig. 2A. The hPN-1, mPN-1 and PAl-1 non-adsorbed phage 
ELISA presented in Fig. 2B highlights the distinct recognition of all $4 \mathrm{VHHs}$ for hPN-1 and $\mathrm{mPN}-1$ as well as their non-recognition of hPAl-1.

\section{Characterization of anti-PN-1 VHHs obtained from the synthetic library}

The purified $\mathrm{VHHs}$ were analysed for their interaction with PAl-1 and both $\mathrm{hPN}-1$ and $\mathrm{mPN}-1$. In line with the initial screening, none of the 4 selected $\mathrm{VHH}$ displayed relevant binding to human or murine PAI-1 (Fig. 3A-B). In contrast, VHHs H12, B11, F06 and A08 all displayed dose-dependent binding to both human and murine PN-1 (Fig. 3C-D). To assess the inhibitory activity of the different $\mathrm{VHHs}$ towards $\mathrm{PN}-1$, we next performed an assay measuring thrombin activity in the presence of $\mathrm{PN}-1$ and the various $\mathrm{VHHs}$. Although being most efficient in binding to both $\mathrm{hPN}-1$ and $\mathrm{mPN}-1, \mathrm{VHH} H 12$ interfered only partially with $\mathrm{PN}-1$-mediated inhibition of thrombin activity, restoring thrombin activity to $74 \pm 5 \%$ and $53 \pm 17 \%$ for $\mathrm{hPN}-1$ and $\mathrm{mPN}-1$, respectively (Fig. 3E-F). VHHs B11, F06 and A08 proved more efficient in lifting hPN-1 inhibition of thrombin, with a recovery of thrombin activity of $100 \pm 7 \%$ for B11, $100 \pm 5 \%$ for F06 and $100 \pm 11 \%$ for A08, (Fig. 3E). A similar potent inhibitory capacity was also observed for $\mathrm{mPN}-1$ : $92 \pm 10 \%$ for $\mathrm{B} 11,96 \pm 9 \%$ for $\mathrm{F} 06$ and $94 \pm 14 \%$ for A08 (Fig. 3F). None of these VHHs affected inhibition of u-PA by PAl-1 (Fig. 3G). In conclusion, this second selection strategy did generate $\mathrm{VHHs}$ being selective and inhibitory towards both $\mathrm{hPN}-1$ and $\mathrm{mPN}-1$.

\section{Determination of the IC50 for B11, F06, A08 VHHs}

In order to determine the half maximum inhibitory concentration of B11, F06 and A08 towards hPN-1 and mPN-1, we incubated various concentrations of $\mathrm{VHHs}$ with $10 \mathrm{nM} \mathrm{PN}-1$ and $1 \mathrm{nM}$ thrombin. The degradation of PNAPEP-0238 substrate was followed for 2 hours. The calculated IC50 values for the tested VHHs towards $h P N-1$ were $0.05 \pm 0.01 \mu \mathrm{M}$ for B11, $0.29 \pm 0.03 \mu \mathrm{M}$ for $\mathrm{F} 06$, and $0.96 \pm 0.39 \mu \mathrm{M}$ for $\mathrm{A} 08$ (Fig. $4 \mathrm{~A}$ ). Using $\mathrm{mPN}-1$, the respective calculated values of IC50 were $1.58 \pm 0.24 \mu \mathrm{M}$ for B11, $0.56 \pm 0.13 \mu \mathrm{M}$ for F06, and $2.88 \pm 0.77 \mu \mathrm{M}$ for $\mathrm{A} 08$ and (Fig. $4 \mathrm{~A}$ ). To increase the inhibitory effect of the VHHs especially towards mPN-1, we next generated 3 different bivalent constructs, B11bv, B11F06 and B11A08 (Fig. 4B). Following this engineering step, we verified whether the purified bivalent VHHs had kept their ability to bind hPN-1 and mPN-1 (Fig. 5A-B). We also confirmed that they still did not recognize PAI-1 (not shown).

The IC50 of the bivalent VHHs were markedly improved compared to monovalent VHHs with values of $41 \pm 7 \mathrm{nM}$ for $\mathrm{B} 11 \mathrm{bv}, 62 \pm 6 \mathrm{nM}$ for $\mathrm{B} 11 \mathrm{~F} 06$ and $142 \pm 28 \mathrm{nM}$ for $\mathrm{B} 11 \mathrm{~A} 08$ towards $\mathrm{hPN}$ 1. For $\mathrm{mPN}-1$, the IC50 were also improved with values of $825 \pm 9 \mathrm{nM}, 414 \pm 141 \mathrm{nM}$ and $524 \pm 174 \mathrm{nM}$ for B11bv, B11F06 and B11A08 respectively (Fig. 5C). 
In an attempt to identify the binding region of the $\mathrm{VHHs}$ on $\mathrm{PN}-1$, we performed $\mathrm{BLI}$-analysis to test the interaction between a peptide covering the RCL region of $\mathrm{PN}-1$ (either intact or after cleavage by thrombin) and the bivalent VHHs. All three bivalent sdAbs bound efficiently to the RCL peptide, demonstrating that they are directed against this area of the protein (Fig. $5 D)$. Binding to this peptide was strongly reduced for each bivalent construct upon RCL cleavage by thrombin. These data are compatible with $\mathrm{VHH}$ B11 binding to the C-terminal portion of the RCL (which is released from the sensor after thrombin cleavage) or to an epitope overlapping the P1-P'1 cleavage site. None of the VHHs appear to recognize the Nterminal portion of the RCL (which remains bound to the sensor after thrombin cleavage). The data do not distinguish between F06 and A08 binding to the C-terminal portion of the RCL or to an epitope outside the RCL.

\section{Effect of bivalent VHHs on in vitro coagulation assays.}

To test the effect of bivalent VHHs on coagulation, we performed modified PT and aPTT coagulation assays with $\mathrm{mPN}-1$ using murine plasma.

First, a PT was developed using wild-type plasma incubated with a prothrombin deficient lyophilised plasma in order to be able to use only small quantities of mPN-1. Using this modified assay, PT was $69.0 \pm 2.4 \mathrm{sec}$ and increased to $123.8 \pm 6.6 \mathrm{sec}$ after addition of $62.5 \mathrm{nM}$ mPN-1 (Fig. 6A). At a concentration of $288 \mathrm{nM}$, all three bivalent $\mathrm{VHHs}$ were able to restore the PT, while not affecting PT in the absence of added mPN-1 $(83.5 \pm 1.1 \mathrm{sec}$ for $\mathrm{B} 11 \mathrm{bv}$; $83.3 \pm 1.5 \mathrm{sec}$ for $\mathrm{B} 11 \mathrm{~F} 06 ; 93.2 \pm 4.4 \mathrm{sec}$ for $\mathrm{B} 11 \mathrm{~A} 08)$. In this assay, $\mathrm{B} 11 \mathrm{~A} 08$ was slightly less efficient that the other two VHHs.

We also tested the effect of bivalent VHHs in a modified aPTT (Fig. 6B). Similar to the PT, we designed specific conditions where aPTT is increased, by using F8-deficient murine plasma in order to make the test more sensitive to PN-1. aPTT in F8-deficient murine plasma was $97.0 \pm 2.7 \mathrm{sec}$ and increased 1.6 -fold to $148.4 \pm 7.9 \mathrm{sec}$ when $\mathrm{mPN}-1$ was added. The three $\mathrm{VHHs}$ decreased significantly the aPTT, with B11F06 being most efficient $(112.5 \pm 7.0 \mathrm{sec}$; Fig. 6B).

We next investigated whether our bivalent $\mathrm{VHHs}$ were also able to inhibit endogenous $\mathrm{PN}-1$ present in platelet alpha granules. For this experiment, supernatant from non-activated or TRAP-activated platelets was used as a source of PN-1. The efficacy of secreted PN-1 in inhibiting thrombin activity was thus investigated. As expected, when supernatant from nonactivated platelets was incubated with thrombin, no inhibitory effect was measured since PN1 had not been released from platelet $\alpha$-granules (Fig. 6C). In contrast, residual thrombin activity dropped to $18 \pm 15 \%$ in the presence of supernatant derived from TRAP-activated platelets (Fig. 6D). The bivalent VHHs abolished the inhibition of thrombin activity by the 
secreted platelet $\mathrm{PN}-1$, thrombin activity being restored to $97 \pm 23 \%$ for $\mathrm{B} 11 \mathrm{bv}, 88 \pm 21 \%$ for B11F06 and $100 \pm 15 \%$ for B11A08. 


\section{DISCUSSION}

Many physiological systems utilize proteins that share structural homologies. One example is the coagulation cascade, in which vitamin K-dependent serine proteases participate as proand anti-coagulant enzymes. From an evolutionary perspective, these structurally homologous proteins seem to originate from gene duplications. ${ }^{28}$ Such structural homology is also observed in another group of proteins that participates in haemostasis and beyond, ie. serpins. The vast majority of the natural inhibitors of thrombin, the key final effector of the coagulation cascade, are members of the serpin family. ${ }^{1}$ Among them is protease nexin-1 (PN-1), encoded by SERPINE2, which has emerged as a crucial player in thrombin regulation. To better understand the importance of $\mathrm{PN}-1$ mediated thrombin inhibition in the diverse in vitro and in vivo experimental models, as well as to potentially develop therapeutic tools, we aimed to generate neutralizing antibodies against PN-1.

The generation of antibodies against PN-1 has been hampered by the fact that there is a large structural and functional homology between $\mathrm{PN}-1$ and its nearest phylogenetical familymember, PAI-1, a protein encoded by SERPINE1. PN-1 shares $41 \%$ homology with PAI$1^{2,26,29}$ and has a target protease specificity overlapping with the one of PAI- $1{ }^{6}$ Such properties have complicated the generation of specific anti-PN-1 antibodies, as illustrated by the cross-reactivity of virtually all commercially available anti-PN-1 antibodies with PAI-1. Therefore, it was within the objectives of this study to design a selection process that would favour the isolation of single-domain antibodies that bind and inhibit PN-1 but leave PAI-1 unaffected.

In a first series of experiments, we selected $\mathrm{VHHs}$ against $\mathrm{PN}-1$ after phage-display screening using a llama library, obtained after immunization with both hPN-1 and mPN-1. Despite the negative selection using PAI-1 coated beads, only two out of 377 selected clones proved specific for $\mathrm{PN}-1$, with minimal binding to PAI-1. These data suggest that negative pre-selection of phages may indeed result in VHHs that have improved specificity, although the efficacy of this approach remains weak. Unfortunately, none of the two PN-1 specific clones, designated KB-PN1-01 and KB-PN1-02, displayed sufficient inhibitory activity towards $\mathrm{hPN}-1$ and $\mathrm{mPN}-1$. Although these $\mathrm{VHHs}$ may find use in other types of applications (eg. as reagents for flow-cytometry, Elisa, Western blots or immunofluorescence), an additional search was needed to obtain inhibitory VHHs.

The lack of sufficient numbers of $\mathrm{PN}-1$ specific $\mathrm{VHHs}$ may originate from different possibilities: first, the majority of $\mathrm{PN}-1$ peptides exposed for antibody generation in the llama overlap to a large extent with similar epitopes in PAI-1; second, PN-1 is a rather nonimmunogenic protein, reducing the immunogenic response during the immunization process; third, the final size of the llama-derived library is too small to obtain sufficient numbers of PN1 specific VHHs, and an extended diversity of the library would be needed. A second series 
of screening was therefore performed using a unique humanized $\mathrm{VHH}$ synthetic antibody library coding for $3 \times 10^{9} \mathrm{VHHs}$, ie. 30 -fold more diverse than the llama-derived library. ${ }^{27}$ This synthetic library was designed to produce stable, high-affinity binders without the need for animal immunization.

The use of the synthetic naïve library appeared to be successful, as $4 \mathrm{VHHs}$ were identified that were not only specific to $\mathrm{hPN}-1$ and $\mathrm{mPN}-1$, with no detectable binding to PAl-1, but also having strong inhibitory activity towards $\mathrm{PN}-1$. These VHHs were named $\mathrm{H} 12, \mathrm{~B} 11, \mathrm{~F} 06$ and A08. B11, F06 and A08 were able to fully neutralize PN-1 in thrombin-based activity assays, whereas $\mathrm{H} 12$ displayed partially inhibitory activity. The analysis of their sequences revealed a relatively conserved CDR-2 for $\mathrm{H} 12, \mathrm{~B} 11$ and $\mathrm{F} 06$, whereas no consensus sequences were present in CDR-1 and CDR-3, apart from being enriched in hydrophilic amino acids (Fig. 2). The most important variability between these $4 \mathrm{VHHs}$ was found in the CDR-3, with lengths varying from 9 residues for $\mathrm{H} 12$ and $\mathrm{A} 08$ to 15 and 18 residues for $\mathrm{F} 06$ and $\mathrm{B} 11$, respectively (Fig. 2). The presence of a long CDR-3 sequence is often seen in the VHHs and allows enlarging the contact surface of the antibody fragment with the antigen. However, we could not observe a clear correlation between CDR-3 size and affinity, as the $\mathrm{H} 12$ and B11 (having the shortest and longest CDR-3, respectively) displayed more efficient binding to hPN-1 compared to F06 and A08 (Fig. 3). In contrast, B11 and F06 were more efficient than $\mathrm{H} 12$ and $\mathrm{A} 08$ in neutralizing $\mathrm{PN}-1$ activity towards thrombin, suggesting that the larger antigenbinding surface contributes to the interference with $\mathrm{PN}-1$ /thrombin interactions.

We noticed that the monovalent $\mathrm{VHHs}$ were relatively weak inhibitors of $\mathrm{PN}-1$, with $\mathrm{IC}_{50}$ values varying between 50 and $960 \mathrm{nM}$. By generating a series of bivalent and bi-paratopic variants, we anticipated to increase the inhibitory potential of these VHHs. Whereas a modest effect was observed on the $\mathrm{IC}_{50}$ between $\mathrm{B} 11$ and $\mathrm{B} 11 \mathrm{bv}$ with regard to $\mathrm{hPN}-1$, this value was reduced by 2 -fold for $\mathrm{mPN}-1$ (Fig. $4 \mathrm{~A} \& 5 \mathrm{C}$ ). Reductions in $\mathrm{IC}_{50}$ values varying between 4- and 7-fold were also observed for both other combinations (B11F06 and $\mathrm{B} 11 \mathrm{A08})$, with regard to $\mathrm{hPN}-1$. Moreover, a significant 5-fold reduction of the $\mathrm{IC}_{50}$ was obtained for B11A08, with regard to $\mathrm{mPN}-1$. One would anticipate that the presence of $\mathrm{B} 11$ plays a major role in increasing the affinity for hPN-1 when combined with F06 and A08 as well as for mPN-1 when combined with A08 (Fig. 4A \& 5C). This suggests an additive effect of the presence of both $\mathrm{VHHs}$ in the inhibition of PN-1.

Given the inhibitory activity of the VHHs, we explored the possibility that the respective epitopes of the VHHs were located within the RCL-sequence of PN-1. Indeed, each of the VHHs was able to bind to an immobilized biotinylated peptide encompassing the reactive center loop (RCL)-sequence (Fig. 5D). Moreover, binding virtually disappeared following proteolysis of the peptide by thrombin, which releases the C-terminal portion of the peptide. It seems plausible that the $\mathrm{VHHs}$ recognize an epitope around or C-terminal to the thrombin- 
cleavage site. Most likely, this would represent a linear epitope. The location of this epitope is in agreement with the inhibitory activity of the VHHs, as they would directly compete with thrombin for binding to the RCL. In addition, it is worth noting that in contrast to the remainder of the proteins, the RCL sequences of PAI-1 and PN-1 (residues P9-P'9) share $<40 \%$ identity, which could explain the specificity for PN-1 over PAl-1. Finally, the RCL is a rather flexible structure, and consequently, the VHHs may not recognize not all of the conformations that this flexible structure can adopt. This might potentially explain why the monovalent $\mathrm{VHHs}$ are relatively weak inhibitors.

To further validate the utility of these $\mathrm{VHHs}$, they were tested under more complex conditions, ie. in plasma rather than a system using purified proteins. Since PN-1 is absent in plasma, spiking experiments were performed in which mPN-1 was added to murine FVIIIdeficient plasma. In both the aPTT- and PT-assays, final molar concentrations of PN-1 were 2.2- and 22-fold below that of antithrombin, the main thrombin inhibitor in plasma. The notion that the clotting times were prolonged indicates that PN-1 actively inhibits thrombin under these conditions, and is thus able to act in parallel to other anticoagulant proteins such as antithrombin. Moreover, the observation that the $\mathrm{VHHs}$ in turn neutralized the effect of $\mathrm{PN}-1$ may suggest that the $\mathrm{VHH}$ display little if any cross-reactivity with other proteins present in plasma. Further, we have previously shown, that platelets release $\mathrm{PN}-1$ following their activation, and that this $\mathrm{PN}-1$ impairs the generation of thrombin. Indeed, by using supernatants of non-activated and TRAP-activated platelets, we could confirm the release of a thrombin-inhibitory molecule (Fig. 6C-D). Interestingly, this inhibitory effect could be neutralized by the addition of $\mathrm{VHHs,} \mathrm{demonstrating} \mathrm{that} \mathrm{they} \mathrm{are} \mathrm{able} \mathrm{to} \mathrm{interact} \mathrm{with} \mathrm{and}$ inhibit PN-1 that is released from platelets.

Altogether, we have developed a strategy for the development of inhibitory VHHs targeting $\mathrm{PN}-1$, which do not cross-react with PAI-1. These VHHs can be used as research tools to better understand the role of PN-1 in physiological and pathological processes. In addition, they may be explored for their potential therapeutic application in haemophilia treatment for instance.

\section{Acknowledgements}

The study received financial support from the Agence Nationale de la Recherche (ANR-14OHRI-0013) (M-C Bouton and CV Denis) and from the Société Française d'Hématologie (SFH) (S. Ferrière).

\section{Conflict of interest:}


OCD, PJL, MCB and CVD are inventors on a patent application regarding single-domain antibodies against protease nexin-1. The other authors have no relevant conflict of interest to declare.

\section{Author contributions:}

CK, KA, LV, VA, performed experiments and analyzed data.

ODC, MCB, YB, PJL and CVD conceived and supervised the study.

CK, PJL, MCB and CVD wrote the manuscript.

All authors contributed to the editing of the final manuscript. 


\section{REFERENCES}

1. Huntington JA. Serpin structure, function and dysfunction. J Thromb Haemost 2011; 9 Suppl 1:26-34.

2. McGrogan M, Kennedy J, Ping Li M, Hsu C, Scott RW, Simonsen CC, Baker JB. Molecular Cloning and Expression of Two Forms of Human Protease Nexin I. Nat Biotechnol 1988; 6:172-7.

3. Bouton MC, Boulaftali $Y$, Richard B, Arocas V, Michel JB, Jandrot-Perrus $M$. Emerging role of serpinE2/protease nexin-1 in hemostasis and vascular biology. Blood 2012; 119:2452-7.

4. Boulaftali Y, Venisse L, Richard B, Taieb S, Monard D, Alessi M, Bryckaert M, Jandrot-perrus M, Bouton M. Anticoagulant and antithrombotic properties of platelet protease nexin-1. Blood 2010; 115:97-106.

5. Evans DL, McGrogan M, Scott RW, Carrell RW. Protease specificity and heparin binding and activation of recombinant protease nexin I. J Biol Chem 1991; 266:22307-12.

6. Scott RW, Bergman BL, Bajpai A, Hersh RT, Rodriguez H, Jones BN, Barreda C, Watts S, Baker JB. Protease nexin. Properties and a modified purification procedure. J Biol Chem 1985; 260:7029-34.

7. Knauer DJ, Majumdar D, Fong PC, Knauer MF. SERPIN regulation of factor Xla. The novel observation that protease nexin 1 in the presence of heparin is a more potent inhibitor of factor Xla than C1 inhibitor. J Biol Chem 2000; 275:37340-6.

8. Hermans JM, Stone SR. Interaction of activated protein C with serpins. Biochem J 1993; 295 ( Pt 1):239-45.

9. Muhl L, Nykjaer A, Wygrecka M, Monard D, Preissner KT, Kanse SM. Inhibition of PDGF-BB by Factor VII-activating protease (FSAP) is neutralized by protease nexin-1, and the FSAP-inhibitor complexes are internalized via LRP. Biochem J 2007; 404:191-6.

10. Boulaftali Y, Ho-Tin-Noe B, Pena A, Loyau S, Venisse L, François D, Richard B, Arocas V, Collet J-P, Jandrot-Perrus M, et al. Platelet protease nexin-1, a serpin that strongly influences fibrinolysis and thrombolysis. Circulation 2011; 123:1326-34.

11. Aymonnier K, Kawecki C, Venisse L, Boulaftali Y, Christophe OD, Lenting PJ, Arocas $\mathrm{V}$, de Raucourt E, Denis CV, Bouton M-C. Targeting protease nexin-1, a natural anticoagulant serpin, to control bleeding and improve hemostasis in hemophilia. Blood 2019; 134:1632-44.

12. Pasi KJ, Rangarajan S, Georgiev P, Mant T, Creagh MD, Lissitchkov T, Bevan D, Austin S, Hay CR, Hegemann I, et al. Targeting of Antithrombin in Hemophilia A or B with RNAi Therapy. N Engl J Med 2017; 377:819-28.

13. Eichler $H$, Angchaisuksiri $P$, Kavakli $K$, Knoebl $P$, Windyga J, Jiménez-Yuste $V$, 
Harder Delff P, Chowdary P. Concizumab restores thrombin generation potential in patients with haemophilia: Pharmacokinetic/pharmacodynamic modelling results of concizumab phase 1/1b data. Haemophilia 2019; 25:60-6.

14. Polderdijk SGI, Baglin TP, Huntington JA. Targeting activated protein $C$ to treat hemophilia. Curr Opin Hematol 2017; 24:446-52.

15. Muyldermans S, Atarhouch T, Saldanha J, Barbosa JA, Hamers R. Sequence and structure of $\mathrm{VH}$ domain from naturally occurring camel heavy chain immunoglobulins lacking light chains. Protein Eng 1994; 7:1129-35.

16. Muyldermans S. Single domain camel antibodies: current status. J Biotechnol 2001; 74:277-302.

17. De Meyer T, Muyldermans S, Depicker A. Nanobody-based products as research and diagnostic tools. Trends Biotechnol 2014; 32:263-70.

18. Smolarek D, Bertrand O, Czerwinski M. Variable fragments of heavy chain antibodies (VHHs): a new magic bullet molecule of medicine? Postepy Hig Med Dosw (Online) 2012; 66:348-58.

19. Vu KB, Ghahroudi MA, Wyns L, Muyldermans S. Comparison of llama VH sequences from conventional and heavy chain antibodies. Mol Immunol 1997; 34:1121-31.

20. Selbonne S, Azibani F, latmanen S, Boulaftali Y, Richard B, Jandrot-Perrus M, Bouton M-C, Arocas V. In vitro and in vivo antiangiogenic properties of the serpin protease nexin-1. Mol Cell Biol 2012; 32:1496-505.

21. Bezeaud A, Denninger $\mathrm{MH}$, Guillin $\mathrm{MC}$. Interaction of human alpha-thrombin and gamma-thrombin with antithrombin III, protein C and thrombomodulin. Eur J Biochem 1985; 153:491-6.

22. Aymé G, Adam F, Legendre P, Bazaa A, Proulle V, Denis CV, Christophe OD, Lenting PJ. A Novel Single-Domain Antibody Against von Willebrand Factor A1 Domain Resolves Leukocyte Recruitment and Vascular Leakage During Inflammation-Brief Report. Arterioscler Thromb Vasc Biol 2017; 37:1736-40.

23. Behar $G$, Sibéril $S$, Groulet $A$, Chames $P$, Pugnière $M$, Boix $C$, Sautès-Fridman $C$, Teillaud J-L, Baty D. Isolation and characterization of anti-FcgammaRIII (CD16) Ilama singledomain antibodies that activate natural killer cells. Protein Eng Des Sel 2008; 21:1-10.

24. Barbon E, Ayme G, Mohamadi A, Ottavi J-F, Kawecki C, Casari C, Verhenne S, Marmier S, van Wittenberghe $\mathrm{L}$, Charles $\mathrm{S}$, et al. Single-domain antibodies targeting antithrombin reduce bleeding in hemophilic mice with or without inhibitors. EMBO Mol Med 2020; :e11298.

25. Hoogenboom HR, Griffiths AD, Johnson KS, Chiswell DJ, Hudson P, Winter G. Multisubunit proteins on the surface of filamentous phage: methodologies for displaying antibody (Fab) heavy and light chains. Nucleic Acids Res 1991; 19:4133-7. 
26. Irving JA, Pike RN, Lesk AM, Whisstock JC. Phylogeny of the serpin superfamily: implications of patterns of amino acid conservation for structure and function. Genome Res $2000 ; 10: 1845-64$.

27. Moutel S, Bery N, Bernard V, Keller L, Lemesre E, De Marco A, Ligat L, Rain JC, Favre G, Olichon A, et al. NaLi-H1: A universal synthetic library of humanized nanobodies providing highly functional antibodies and intrabodies. eLife 2016; 5.

28. Davidson CJ, Tuddenham EG, McVey JH. 450 million years of hemostasis. J Thromb Haemost 2003; 1:1487-94.

29. Sommer J, Gloor SM, Rovelli GF, Hofsteenge J, Nick H, Meier R, Monard D. cDNA sequence coding for a rat glia-derived nexin and its homology to members of the serpin superfamily. Biochemistry 1987; 26:6407-10. 


\section{LEGENDS}

Figure 1: Identification and characterization of PN-1-specific VHHs by phage display

A. Summary of clones selection after 3 rounds of phage display leading to the identification of 2 specific PN-1 nanobodies named KB-PN1-01 and KB-PN1-02.

B. Representative Biolayer interferometry (BLI)-analysis graphs (Octet) of molecular binding between monovalent $\mathrm{VHHs}$ and $\mathrm{hPN}-1, \mathrm{mPN}-1$ or hPAl-1. Twenty-five $\mu \mathrm{g} / \mathrm{mL}$ of monovalent VHHs were coated on the biosensor, and association with $1 \mu \mathrm{M}$ of hPN-1, mPN-1 or hPAl-1 were measured over an association phase of 900 seconds. Results are expressed as the wavelength shift (in $\mathrm{nm}$ ) generated by the binding of the different molecules.

C. Thrombin (1 $\mathrm{nM}$ ) was incubated with hPN-1 or mPN-1 (20 nM), which were pre-incubated for $30 \mathrm{~min}$ in the absence or presence of monovalent or bivalent VHHs $(20 \mu \mathrm{M})$. Residual thrombin activity was measured by measuring the rate of PNAPEP-0238 hydrolysis. Data (mean $\pm S D ; n=3$ ) represent residual thrombin activity as percentage of thrombin alone.

Figure 2: Identification and sequences of sdAbs isolated from a synthetic library.

A. Amino acid sequences of five sdAbs with the 4 conserved framework regions (FR) responsible of core structure of the immunoglobulin domain and the 3 hypervariable complementarity determining regions (CDR) labelled in red involved in antigen binding.

B. Non-adsorbed phage ELISA determining positive clones obtained after 3 rounds of phage display experiment. Phages were added to plates coated with hPN-1, mPN-1 or hPAl-1. An HRP-conjugated anti-M13 antibody and a colorimetric substrate were used to measure binding. VHH clones which showed a significant ELISA signal in the presence of mPN-1 and $\mathrm{hPN}-1$ and a very low signal in the presence of hPAl-1 were considered specific.

\section{Figure 3: Characterization of VHHs obtained from a synthetic library.}

A-B. Wells were coated with mAb anti-PAl-1 and $2 \mathrm{pg} / \mathrm{mL}$ of hPAl-1 (A) or mPAl-1 (B) were incubated with $\mathrm{VHHs}(10 \mu \mathrm{g} / \mathrm{mL})$. Bound $\mathrm{VHHs}$ were probed with peroxidase-labelled $\mathrm{pAb}$ anti-6X-His tag.

C-D. Wells were coated with $0.5 \mu \mathrm{g}$ of hPN-1 (C) or mPN-1 (D) and incubated with different concentrations of monovalent VHHs $(0.3$ to $20 \mu \mathrm{g} / \mathrm{mL})$. Bound $\mathrm{VHHs}$ were probed with peroxidase-labeled pAb-cMyc tag.

E-F One $\mathrm{nM}$ of thrombin was incubated with $10 \mathrm{nM} \mathrm{hPN-1}(\mathrm{E})$ or $\mathrm{mPN}-1(\mathrm{~F})$ in the presence or absence of $\mathrm{VHHs}(10 \mu \mathrm{M})$. Residual thrombin activity was measured by the rate of PNAPEP-0238-hydrolysis substrate. Data (mean $\pm S D ; n=3-5$ ) represent residual thrombin activity as percentage of thrombin alone. 
G. Urokinase plasminogen activator (u-PA; $1.3 \mathrm{nM}$ ) was incubated with hPAl-1 (10 nM) in the absence or presence of VHHs $(10 \mu \mathrm{M})$. Residual uPa activity was measured by the rate of PNAPEP-1344-hydrolysis substrate. Data $(n=3-5)$ represent residual u-PA activity as percentage of u-PA alone.

Figure 4: Determination of half maximal inhibitory concentration of monovalent VHHs and strategy to identify and improve the best monovalent VHHs:

A. hPN-1 or mPN-1 were incubated with different concentrations of monovalent VHHs (0-2 $\mu \mathrm{M})$ and $1 \mathrm{nM}$ of thrombin was added to each well. Residual thrombin catalytic activity was measured by assaying the rate of PNAPEP-0238-hydrolysis substrate. Data represent residual thrombin activity as percentage of thrombin alone. Each data point represents an individual measurement. The table recapitulates the IC50 obtained for the monovalent VHHs towards $\mathrm{mPN}-1$ and $\mathrm{hPN}-1$ (mean $\pm \mathrm{SD} ; \mathrm{n}=3$ ).

B. Strategy to select the best monovalent $\mathrm{VHHs}$ leading to the choice of bivalent $\mathrm{VHHs}$ in order to improve their properties.

\section{Figure 5: Characterization of bivalent VHHs:}

A-B. Wells were coated with $0.5 \mu \mathrm{g}$ of human (A) or murine PN-1 (B) and incubated with different concentrations of bivalent $\mathrm{VHHs}(0.3$ to $20 \mu \mathrm{g} / \mathrm{mL})$. Bound $\mathrm{VHHs}$ was probed with peroxidase-labeled pAb 6XHis tag.

C. hPN-1 or mPN-1 (10 nM) were incubated with different concentrations of bivalent VHHs $(0-2000 \mathrm{nM})$ and $1 \mathrm{nM}$ of thrombin was added to each well. Residual thrombin catalytic activity was measured by measuring the rate of PNAPEP-0238-hydrolysis. Residual thrombin catalytic activity was measured by assaying the rate of PNAPEP-0238-hydrolysis substrate. Data represent residual thrombin activity as percentage of thrombin alone. Each data point represents an individual measurement. The table recapitulates the IC50 obtained for the bivalent VHHs towards mPN-1 and hPN-1 (mean \pm SD; $n=3$ ).

D. Representative BLI-analysis graphs (Octet) of $\mathrm{VHH}$ binding $(100 \mu \mathrm{g} / \mathrm{mL})$ to biotinylated peptides encompassing the RCL $(50 \mu \mathrm{g} / \mathrm{mL})$. Immobilized peptides were incubated in the absence (red curve) or presence (blue curve) of thrombin $\left(5 \mathrm{U} / \mathrm{ml}\right.$ ) for $30 \mathrm{~min}$ at $37^{\circ} \mathrm{C}$ before exposure to VHHs. The black curve corresponds to the negative control. Results are expressed as the wavelength shift (in $\mathrm{nm}$ ) generated by the binding of the different molecules.

\section{Figure 6: Ex vivo experiments of bivalent VHHs.}

A. Diluted murine wild-type plasma was incubated with $62.5 \mathrm{nM}$ of $\mathrm{mPN}-1$ and spiked with $288 \mathrm{nM}$ of bivalent $\mathrm{VHHs}$ and prothrombin time (PT) was measured. 
B. Diluted FVIII-deficient murine plasma was incubated with $500 \mathrm{nM}$ of mPN-1 and spiked with $625 \mathrm{nM}$ of bivalent $\mathrm{VHHs}$ and a modified activated partial thromboplastin time (aPTT) was performed.

C-D. $0.1 \mathrm{nM}$ of thrombin was incubated with supernatant derived from non-activated (C) or TRAP-activated (D) platelets $\left(5 \times 10^{8}\right.$ cells $\left./ \mathrm{mL}\right)$ in the presence or absence of $1 \mu \mathrm{M}$ bivalent VHHs. Residual thrombin catalytic activity was measured by the rate of PNAPEP 0238hydrolysis substrate. Data (mean $\pm S D ; n=3-4)$ represent residual thrombin activity as percentage of thrombin alone. 


\section{Figure 1}

A

A

\begin{tabular}{|c|c|c|c|c|c|c|}
\hline \multirow{3}{*}{$\begin{array}{l}1300 \text { colonies = } \\
1300 \mathrm{VHHs}\end{array}$} & $\begin{array}{l}\text { Non adsorbed phage } \\
\text { ELISA }\end{array}$ & \multirow{3}{*}{$\begin{array}{c}377 \text { colonies } \\
\text { hPN-1+ } \\
\text { and/or } \\
\text { mPN-1+ }\end{array}$} & $\begin{array}{l}\text { Non adsorbed phage } \\
\text { ELISA }\end{array}$ & \multirow{3}{*}{$\begin{array}{c}375 \text { clones } \\
\text { hPAl-1 + }\end{array}$} & $\begin{array}{l}\text { Production } \\
\text { and }\end{array}$ & \multirow{3}{*}{ 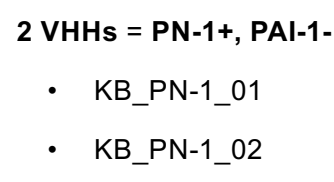 } \\
\hline & screening colony & & screening colony & & purification & \\
\hline & $\begin{array}{c}\text { Ratio } O . D>2 \\
\text { with milk }\end{array}$ & & $\begin{array}{c}\text { Ratio O.D < } 2 \\
\text { with milk }\end{array}$ & & $\begin{array}{l}2 \text { clones } \\
\text { hPAl-1 - }\end{array}$ & \\
\hline
\end{tabular}

B

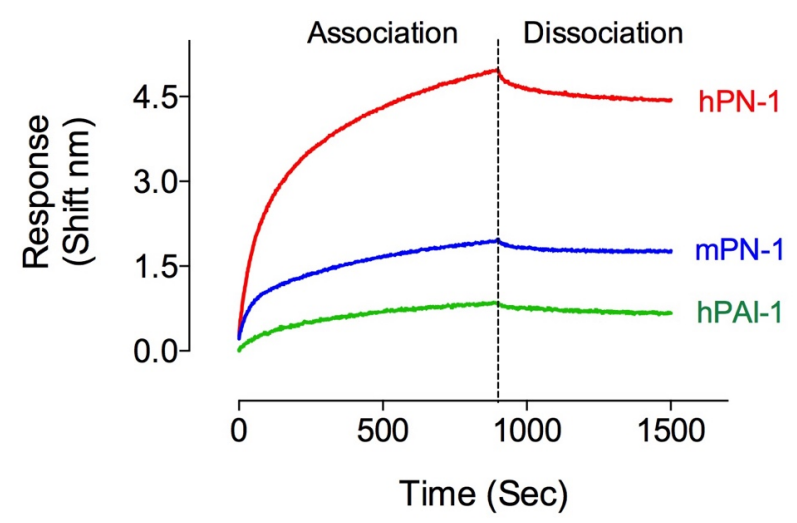

C

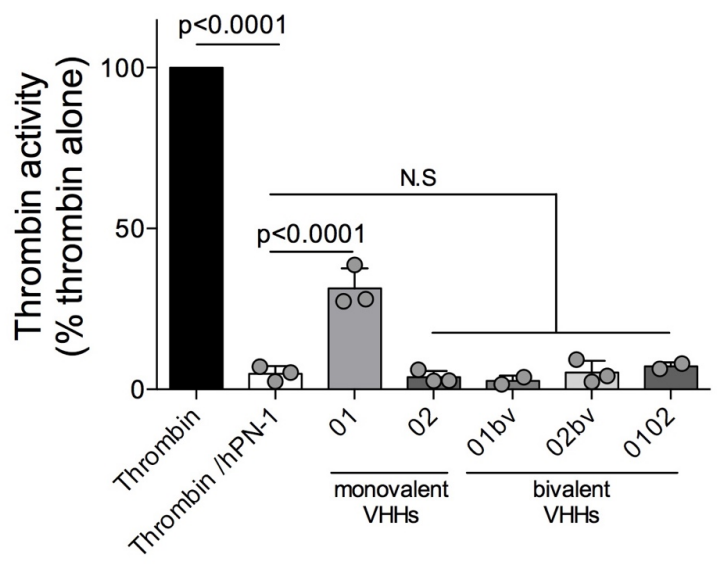

KB-PN-1-02

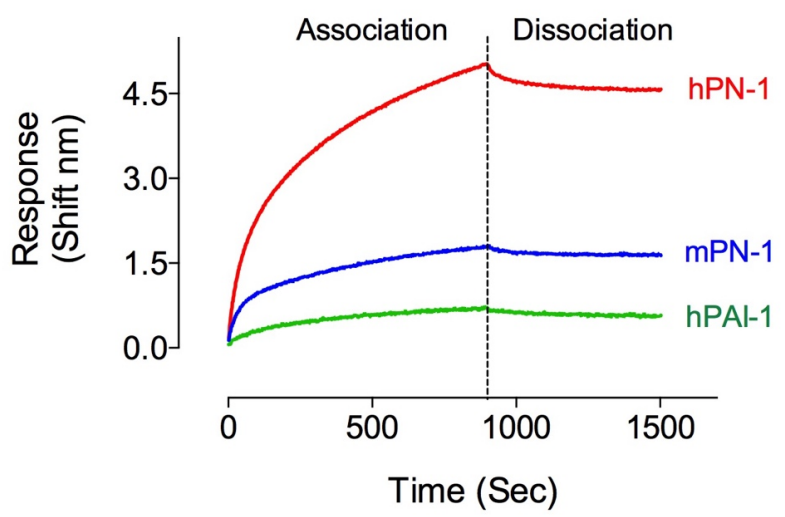

$\mathrm{mPN}-1$

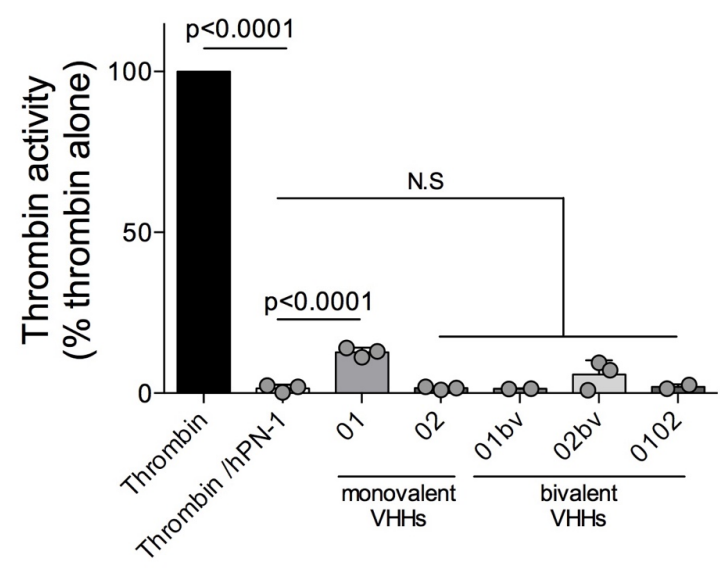

\section{Figure 1: Identification and characterization of PN-1-specific VHHs by phage display}

A. Summary of clones selection after 3 rounds of phage display leading to the identification of 2 specific $\mathrm{PN}-1$ nanobodies named KB-PN1-01 and KB-PN1-02. B. Representative Biolayer interferometry (BLI)-analysis graphs (Octet) of molecular binding between monovalent VHHs and hPN-1, mPN-1 or hPAl-1. Twenty-five $\mu \mathrm{g} / \mathrm{mL}$ of monovalent $\mathrm{VHHs}$ were coated on the biosensor, and association with $1 \mu \mathrm{M}$ of hPN-1, mPN-1 or hPAl-1 were measured over an association phase of 900 seconds. Results are expressed as the wavelength shift (in $\mathrm{nm}$ ) generated by the binding of the different molecules. C. Thrombin $(1 \mathrm{nM})$ was incubated with $\mathrm{hPN}-1$ or $\mathrm{mPN}-1(20 \mathrm{nM})$, which were pre-incubated for $30 \mathrm{~min}$ in the absence or presence of monovalent or bivalent VHHs $(20 \mu \mathrm{M})$. Residual thrombin activity was measured by measuring the rate of S2238hydrolysis. Data (mean $\pm S D ; n=3$ ) represent residual thrombin activity as percentage of thrombin alone. 


\section{Figure 2}

A

CDR-1

CDR-2

CDR-3

MAEVQLQASGGGFVQPGGSLRLSCAASG-RTFRRTA-MGWFRQAPGKEREFVSAIS-ADPNWHS-YYADSVKGRFTISRDNSKNTVYLQMNSLRAEDTATYYCA-TWYGKP**************KKH-YWGQGTQVTVSS MAEVQLQASGGGFVQPGGSLRLSCAASG-STWFREI-MGWFRQAPGKEREFVSAIS-SDPTWHA-YYADSVKGRFTISRDNSKNTVYLQMNSLRAEDTATYYCA-PLAGTESIHWWDPWHESS-YWGQGTQVTVSS

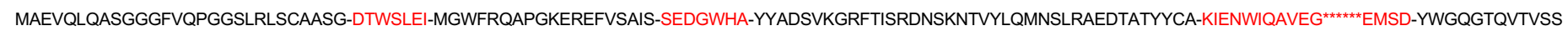
MAEVQLQASGGGFVQPGGSLRLSCAASG-YYSYSST-MGWFRQAPGKEREFVSAIS-FYSDMAH-YYADSVKGRFTISRDNSKNTVYLQMNSLRAEDTATYYCA-AFSKLGKIK ${ }^{\star * \star * \star \star \star \star * \star * * \star * * \star * *-Y W G Q G T Q V T V S S ~}$

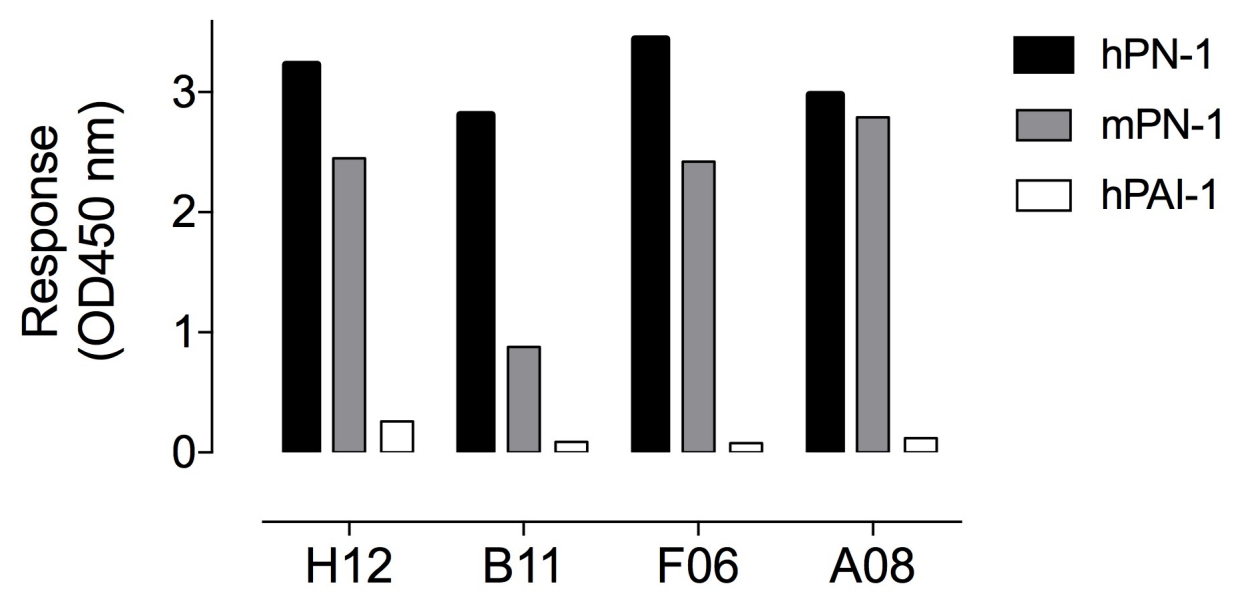

Figure 2 : Identification and sequences of sdAbs isolated from a synthetic library.

A. Amino acid sequences of five sdAbs with the 4 conserved framework regions (FR) responsible of core structure of the immunoglobulin domain and the 3 hypervariable complementarity determining regions (CDR) labelled in red involved in antigen binding. B. Non-adsorbed phage ELISA determining positive clones obtained after 3 rounds of phage display experiment. Phages were added to plates coated with hPN-1, mPN-1 or hPAl-1). An HRP-conjugated anti-M13 antibody and a colorimetric substrate were used to measure binding. $\mathrm{VHH}$ clones with a significant ELISA signal in the presence of $\mathrm{mPN}-1$ and $\mathrm{hPN}-1$ and a very low signal in the presence of hPAl-1 were considered specific. 


\section{Figure 3}

A

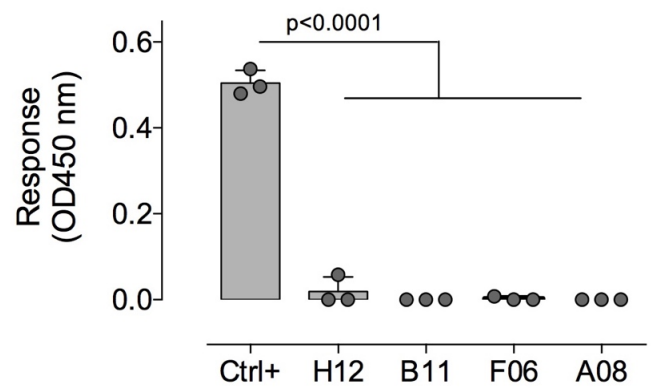

C

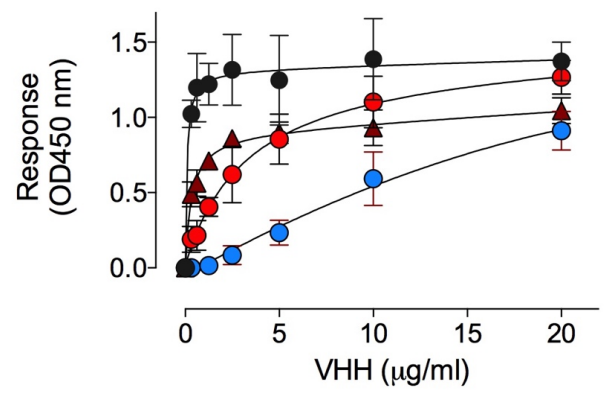

$\mathbf{E}$

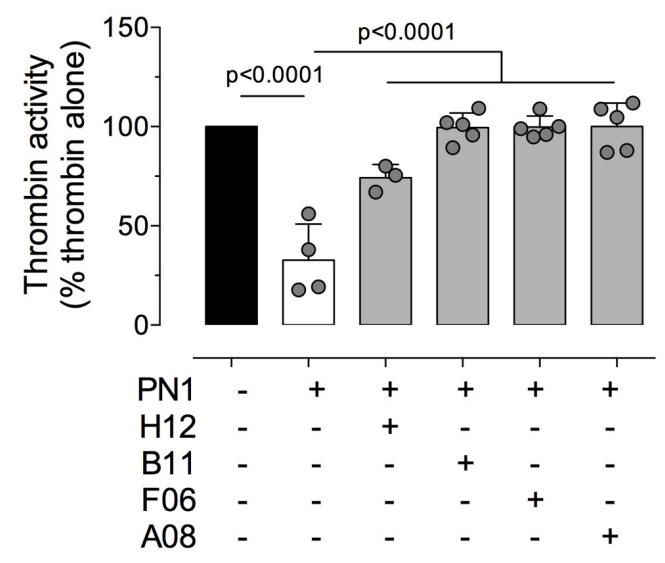

G

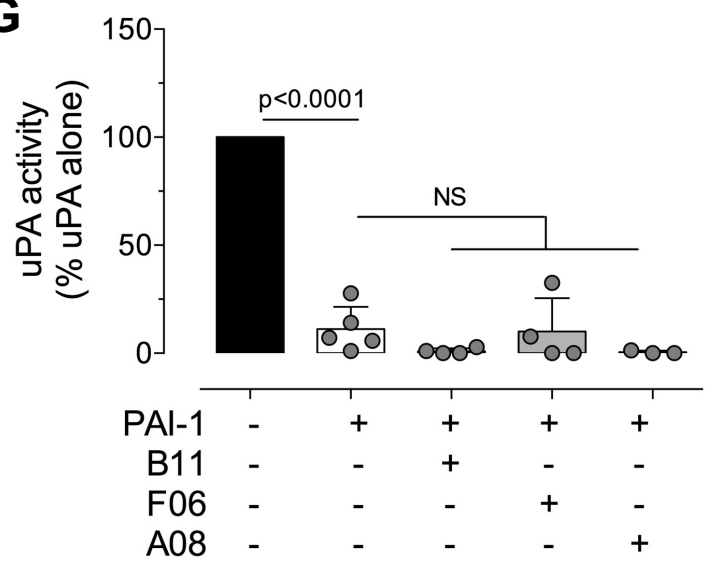

B

mPAl-1

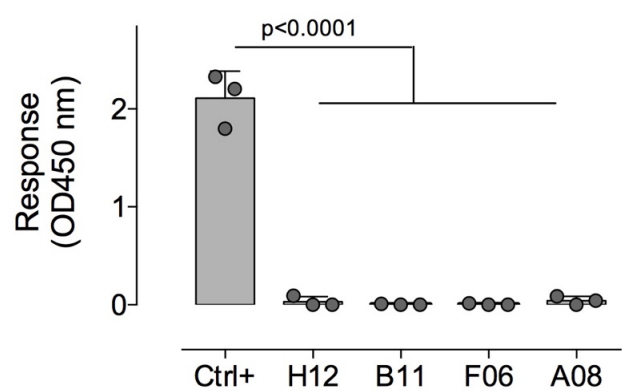

D

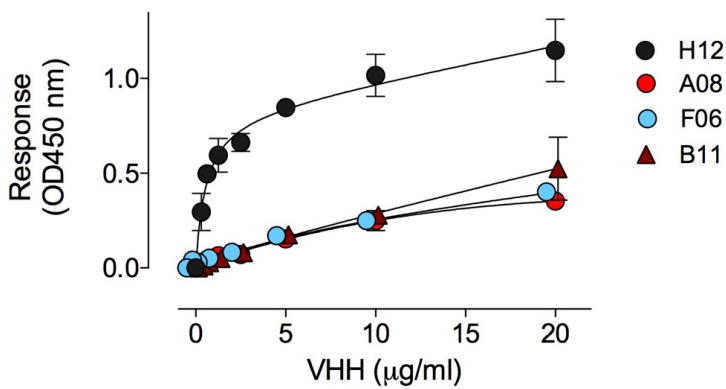

$\mathbf{F}$

$\mathrm{mPN}-1$

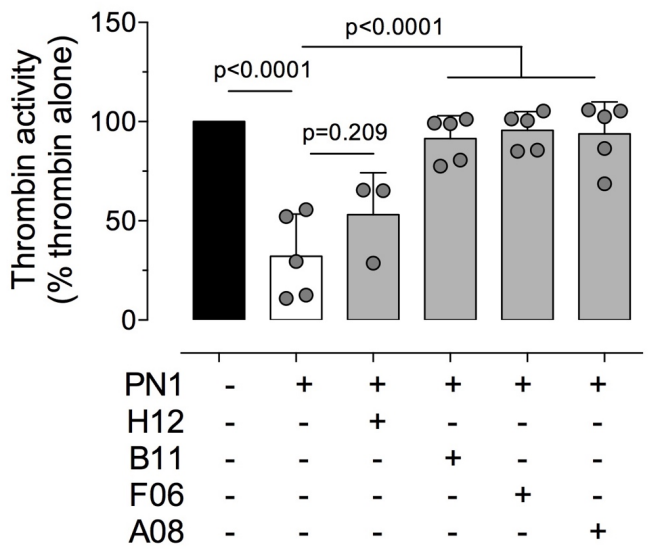

Figure 3 : Characterization of VHHs obtained from a synthetic library. A-B. Wells were coated with $\mathrm{mAb}$ anti-PAl-1 and $2 \mathrm{pg} / \mathrm{mL}$ of hPAl-1 $(E)$ or mPAl-1 $(F)$ were incubated with VHHs $(10 \mu \mathrm{g} / \mathrm{mL})$. Bound $\mathrm{VHHs}$ were probed with peroxidase-labelled $\mathrm{pAb}$ anti-6xHis tag C-D. Wells were coated with $0.5 \mu \mathrm{g}$ of hPN-1 (A) or mPN-1 (B) and incubated with different concentrations of monovalent $\mathrm{VHHs}(0.3$ to $20 \mu \mathrm{g} / \mathrm{mL}$ ). Bound $\mathrm{VHHs}$ were probed with peroxidase-labeled pAb-cMyc tag. E-F One nM of thrombin was incubated with $20 \mathrm{nM}$ $\mathrm{hPN}-1$ (C) or mPN-1 (D) in the presence or absence of $\mathrm{VHHs}$ $(10 \mu \mathrm{M})$. Residual thrombin activity was measured by the rate of PNAPEP-0238-hydrolysis substrate. Data (mean $\pm S D ; n=3-5$ ) represent residual thrombin activity as percentage of thrombin alone. G. Urokinase plasminogen activator (u-PA; $1.3 \mathrm{nM}$ ) was incubated with hPAl-1 (10nM) in the absence or presence of VHHs $(25 \mu \mathrm{M})$. Residual uPa activity was measured by the rate of PNAPEP-1344hydrolysis substrate. Data $(n=3-5)$ represent residual u-PA activity as percentage of u-PA alone. 


\section{Figure 4}

A

Human PN-1
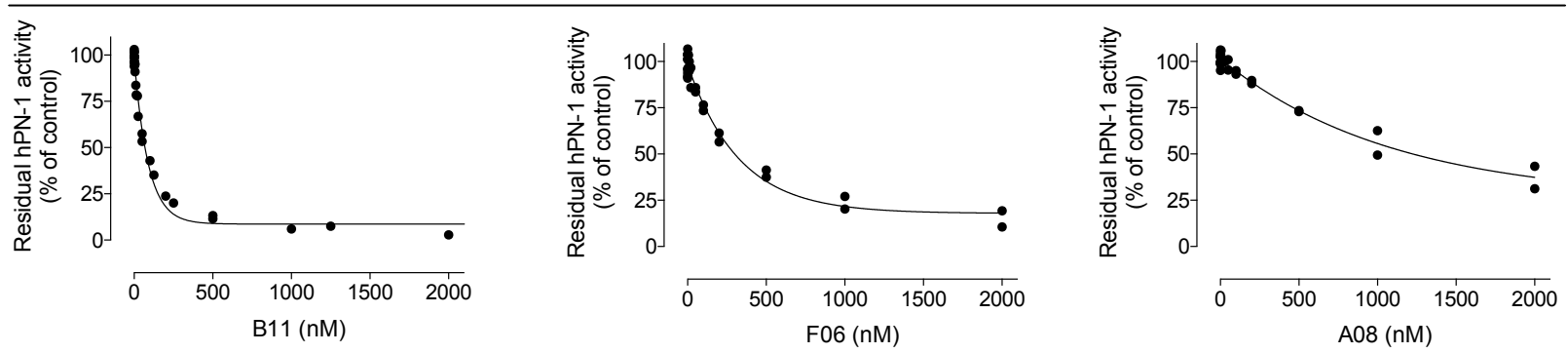

Murine PN-1
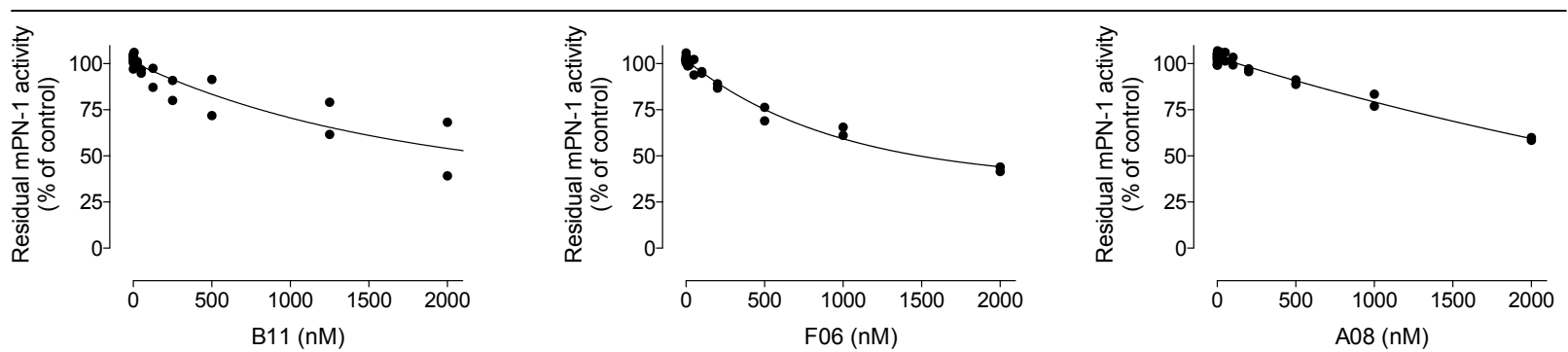

\begin{tabular}{|c|c|c|c|}
\hline VHHs & B11 & F06 & A08 \\
\hline $\mathrm{hPN}-1$ & $0.06 \pm 0.01 \mu \mathrm{M}$ & $0.23 \pm 0.02 \mu \mathrm{M}$ & $1.17 \pm 0.12 \mu \mathrm{M}$ \\
\hline $\mathrm{mPN}-1$ & $1.27 \pm 0.46 \mu \mathrm{M}$ & $0.67 \pm 0.08 \mu \mathrm{M}$ & $3.54 \pm 1.23 \mu \mathrm{M}$ \\
\hline
\end{tabular}

B

Monovalent
sdAbs

Selection of monovalent VHHs

Both PN-1

F06

A08

Binding \& inhibition

Figure 4: Determination of half maximal inhibitory concentration of monovalent VHHs and strategy to identify and improve the best monovalent VHHs: $\mathbf{A}$. hPN-1 or mPN-1 were incubated with different concentrations of monovalent $\mathrm{VHHs}(0-5 \mu \mathrm{M})$ and $1 \mathrm{nM}$ of thrombin was added to each well. Residual thrombin catalytic activity was measured by assaying the rate of PNAPEP-0238-hydrolysis substrate. Data represent residual thrombin activity as percentage of thrombin alone. Each data point represent an individual measurement. The table recapitulates the IC50 obtained for the monovalent VHHs towards mPN-1 and hPN-1 (mean $\pm S D ; n=3)$. B. Strategy to select the best monovalent VHHs leading to the choice of bivalent VHHs in order to improve their properties. 


\section{Figure 5}

A

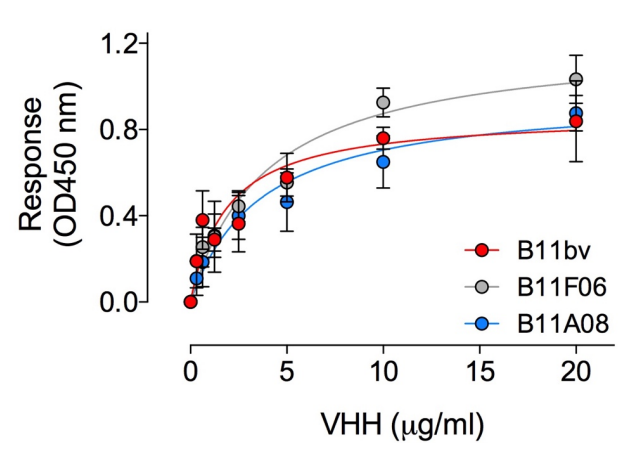

B

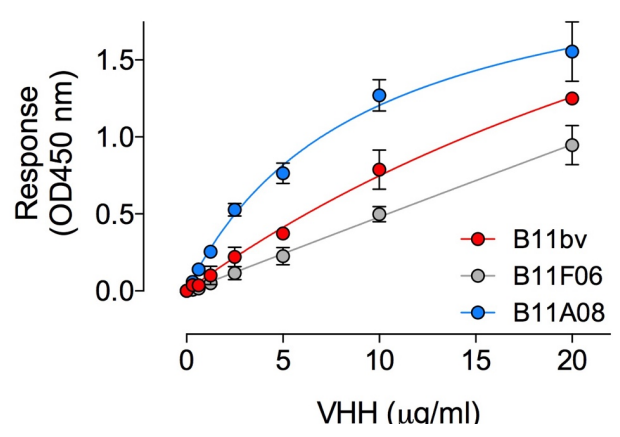

Human PN-1
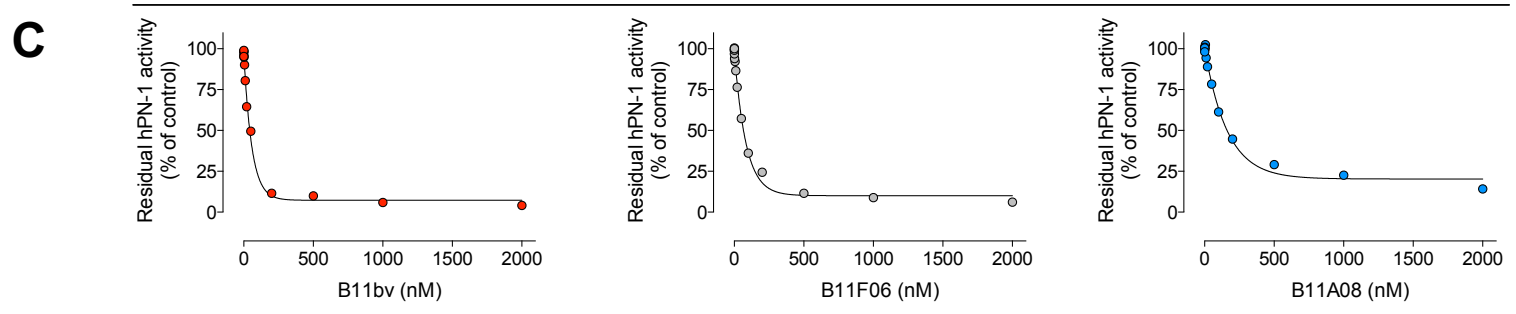

Murine PN-1
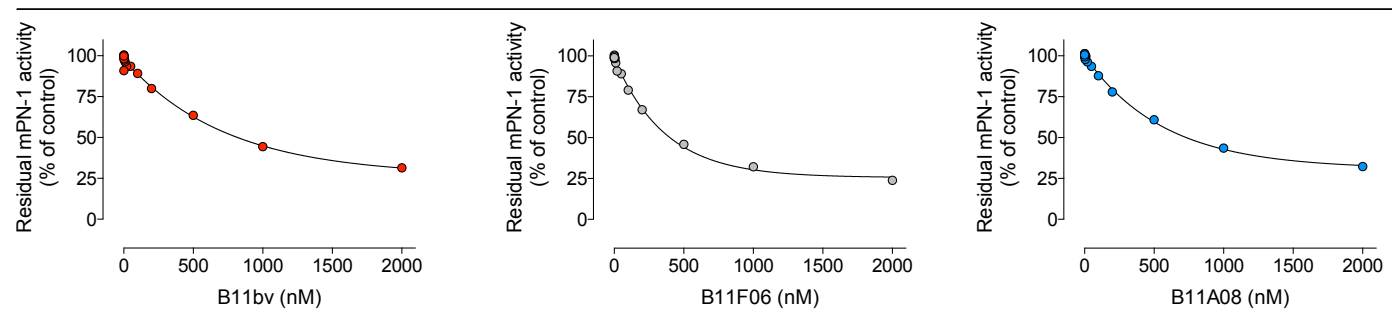

\begin{tabular}{|c|c|c|c|}
\hline VHHs & B11bv & B11F06 & B11A08 \\
\hline $\mathrm{hPN}-1$ & $40 \pm 3 \mathrm{nM}$ & $68 \pm 4 \mathrm{nM}$ & $139 \pm 9 \mathrm{nM}$ \\
\hline $\mathrm{mPN}-1$ & $509 \pm 63 \mathrm{nM}$ & $254 \pm 16 \mathrm{nM}$ & $395 \pm 18 \mathrm{nM}$ \\
\hline
\end{tabular}

D
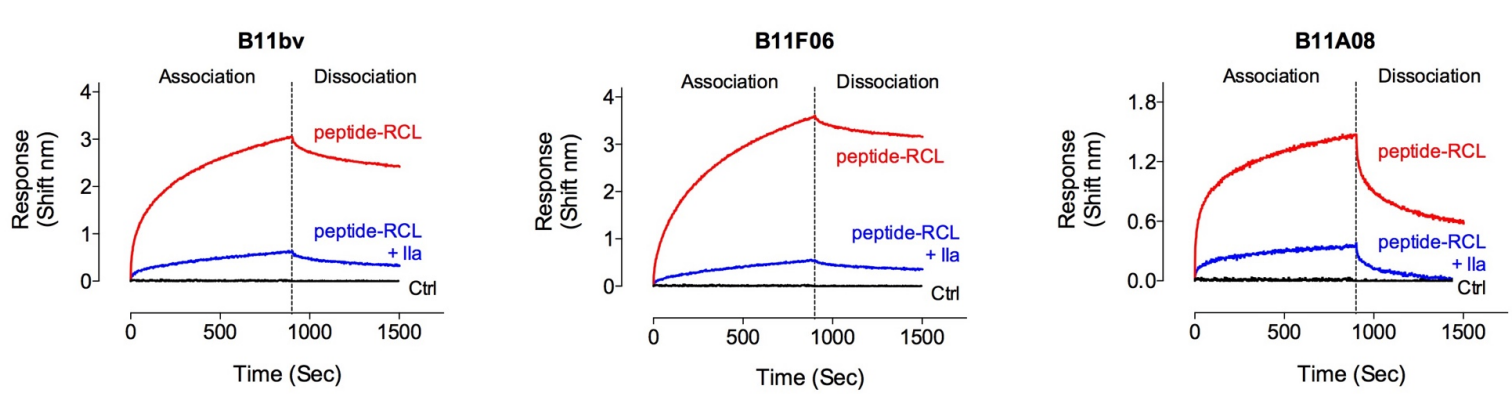

Figure 5: Characterization of bivalent VHHs : A-B. Wells were coated with $0.5 \mu$ g of human (A) or murine PN-1 (B) and incubated with different concentrations of bivalent VHHs $(0.3$ to $20 \mu \mathrm{g} / \mathrm{mL})$. Bound $\mathrm{VHHs}$ was probed with peroxidase-labeled pAb $6 \mathrm{XHis}$ tag. C. hPN-1 or mPN-1 (10 nM) were incubated with different concentrations of bivalent VHHs $(0-5000 \mathrm{nM})$ and $1 \mathrm{nM}$ of thrombin was added to each well. Residual thrombin catalytic activity was measured by measuring the rate of pNAPEP 0238hydrolysis. Residual thrombin catalytic activity was measured by assaying the rate of PNAPEP-0238-hydrolysis substrate. Data represent residual thrombin activity as percentage of thrombin alone. Each data point represent an individual measurement. The table recapitulates the IC50 obtained for the bivalent VHHs towards mPN-1 and hPN-1 (mean \pm SD; $n=3$ ). D. Representative BLIanalysis graphs (Octet) of $\mathrm{VHH}$ binding $(100 \mu \mathrm{g} / \mathrm{mL}$ ) ( to biotinylated peptides encompassing the RCL $(50 \mu \mathrm{g} / \mathrm{mL})$. Immobilized peptides were incubated in the absence (red curve) or presence (blue curve) of thrombin $\left(5 \mathrm{U} / \mathrm{ml}\right.$ )for 30 min at $37^{\circ} \mathrm{C}$ before exposure to VHHs. The black curve corresponds to the negative control. Results are expressed as the wavelength shift (in $\mathrm{nm}$ ) generated by the binding of the different molecules. 


\section{Figure 6}

A

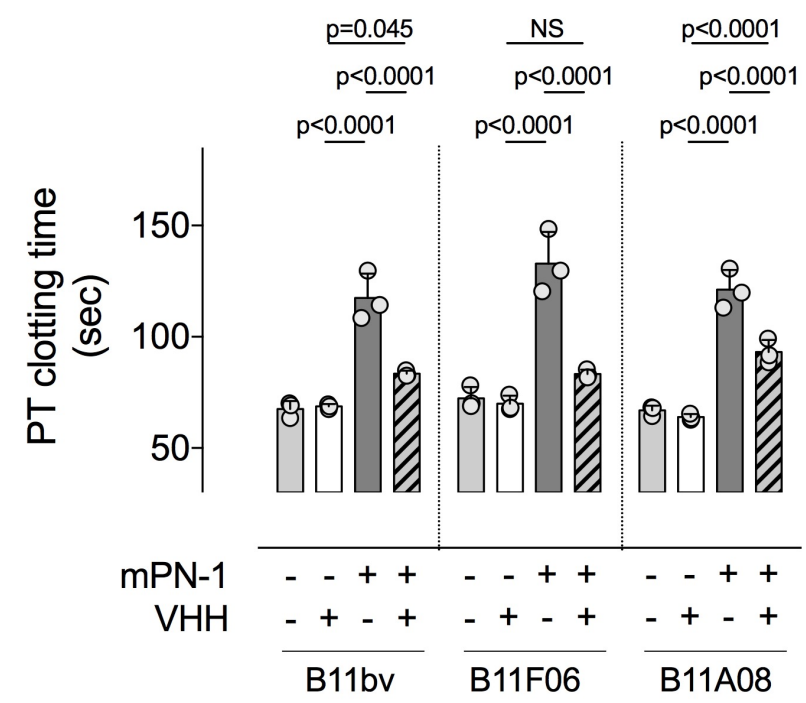

C

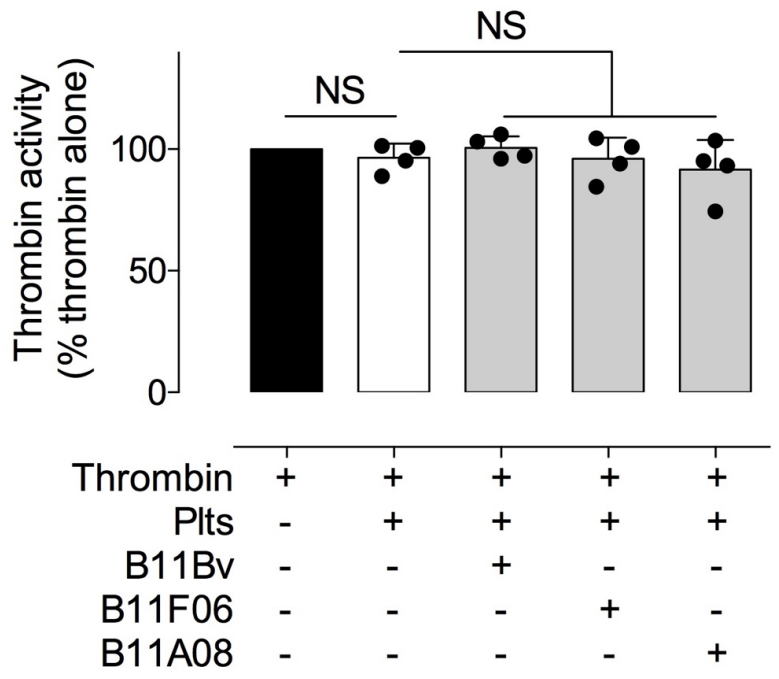

B

Modified activated partial thromboplastin time

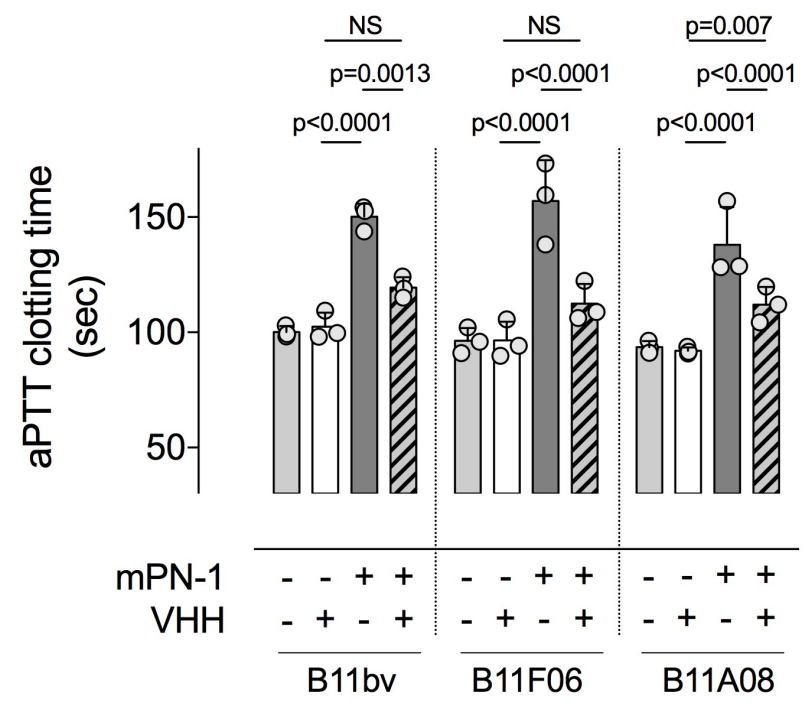

D

activated platelets

$\frac{p=0.002}{p=0.006}$
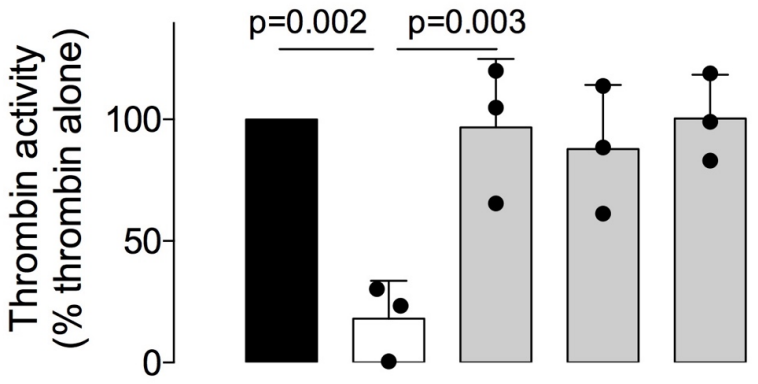

$\begin{array}{rlllll}\text { Thrombin } & + & + & + & + & + \\ \text { Plts } & - & + & + & + & + \\ \text { B11BV } & - & - & + & - & - \\ \text { B11F06 - } & - & - & + & - \\ \text { B11A08 - } & - & - & - & +\end{array}$

Figure 6: Ex vivo experiments of bivalent VHHs. A. Diluted murine wild-type plasma was incubated with $62.5 \mathrm{nM}$ of mPN-1 and spiked with $288 \mathrm{nM}$ of bivalent $\mathrm{VHHs}$ and prothrombin time (PT) was measured. B. Diluted FVIII-deficient murine plasma was incubated with $500 \mathrm{nM}$ of $\mathrm{mPN}-1$ and spiked with $625 \mathrm{nM}$ of bivalent VHHs and a modified activated partial thromboplastin time (aPTT) was performed. C-D. 1 nM of thrombin was incubated with supernatant derived from non-activated (C) or TRAP-activated (D) platelets $\left(5 \times 10^{8}\right.$ cells $\left./ \mathrm{mL}\right)$ in the presence or absence of $10 \mu \mathrm{M}$ bivalent VHHs. Residual thrombin catalytic activity was measured by the rate of pNAPEP 0238-hydrolysis substrate. Data (mean $\pm S D ; n=3-4$ ) represent residual thrombin activity as percentage of thrombin alone. 